OPEN ACCESS

Edited by:

Carolin Regina Löscher, University of Southern Denmark,

Germany

Reviewed by:

Arvind Singh,

Physical Research Laboratory, India Jessica Gier

GEOMAR Helmholtz Centre for Ocean

Research Kiel (HZ), Germany

*Correspondence:

J. Michael Beman

mbeman@ucmerced.edu

Specialty section: This article was submitted to Marine Biogeochemistry, a section of the journal Frontiers in Marine Science

Received: 30 October 2016 Accepted: 09 January 2017

Published: 24 January 2017

Citation:

Wilson J, Abboud S and Beman JM (2017) Primary Production,

Community Respiration, and Net Community Production along Oxygen and Nutrient Gradients: Environmental

Controls and Biogeochemical Feedbacks within and across "Marine

Lakes". Front. Mar. Sci. 4:12

doi: 10.3389/fmars.2017.00012

\section{Primary Production, Community Respiration, and Net Community Production along Oxygen and Nutrient Gradients: Environmental Controls and Biogeochemical Feedbacks within and across "Marine Lakes"}

\author{
Jesse Wilson, Sarah Abboud and J. Michael Beman * \\ Life and Environmental Sciences, Environmental Systems, Quantitative and Systems Biology, University of California, Merced, \\ Merced, CA, USA
}

Declining ocean oxygen content driven by anthropogenic climate change has wide-ranging ramifications for marine ecosystems. These effects are significant but complex at the upper margins of expanding oxygen minimum zones (OMZs), where deoxygenation, and biogeochemical feedbacks to low dissolved oxygen (DO) are regulated by biological production and consumption of DO via gross primary production (GPP) and community respiration (CR). We used "marine lakes"-bodies of seawater surrounded by land-as a natural experimental system for examining the environmental factors that dictate coupling and de-coupling between GPP and CR. Distinct gradients in DO (from fully oxygenated to anoxic conditions), temperature, light, quantity, and quality of organic matter, presence of key nutrients, and microbial community structure occur across multiple stratified meromictic lakes and well-mixed holomictic marine lakes present in Palau. We found consistently high GPP rates in stratified meromictic lakes (>10 mmol $\mathrm{O}_{2} \mathrm{~m}^{-3} \mathrm{~d}^{-1}$ )-especially near the chemocline, where nutrients diffuse upwards from anoxic waters-and a wider range of rates in well-mixed lakes $\left(0.350-57.9 \mathrm{mmol} \mathrm{O}_{2} \mathrm{~m}^{-3} \mathrm{~d}^{-1}\right)$. In contrast to GPP, CR rates were typically lower and less variable across different depths and lakes. Most depths in most lakes were therefore net autotrophic [i.e., net community production (NCP) > 0]. However, experimental additions of ammonium (5 $\mu \mathrm{M})$ and labile organic carbon $(100 \mu \mathrm{M})$ had strong effects on CR, resulting in (i) several-fold increases in CR, (ii) larger increases in $\mathrm{CR}$ in meromictic lakes with chemoclines near the surface, and (iii) the occurrence of net heterotrophy and DO consumption. Our results are indicative of several biogeochemical feedback mechanisms to deoxygenation present 
at the upper margins of shoaling OMZs that are governed by nutrient turnover. In marine lakes, these feedbacks can have strong effects on nutrient uptake and the production and consumption of oxygen, with implications for carbon, nutrient, and oxygen cycling throughout large areas of the ocean.

Keywords: primary production, community respiration, net community production, oxygen loss, nitrogen limitation, marine lakes

\section{INTRODUCTION}

The availability of dissolved oxygen (DO) is a fundamental aspect of marine ecosystems that ultimately controls both the chemical compounds and biota present in a given region of the ocean (Ulloa et al., 2012; Wright et al., 2012; Gilly et al., 2013). DO concentrations are governed by the physiochemical properties of seawater, as well as the biological production and consumption of oxygen and organic matter via photosynthesis and respiration. Throughout the ocean, DO and organic matter are produced only in the well-lit upper ocean, but can be consumed throughout the water column. In areas of high surface production and slow resupply of oxygen at depth (compared to the rate it is respired), DO concentrations are reduced to low levels at depth. Low DO concentrations are found in a variety of marine ecosystems, from enclosed bays and basins to large oxygen minimum zones (OMZs; defined by DO of $<20 \mu \mathrm{M}$; Paulmier and Ruiz-Pino, 2009) located in the Eastern Pacific Ocean and Arabian Sea. In all of these regions, ocean warming has the potential to drive further deoxygenation and oxygen loss through reduced oxygen solubility and changes in physical mixing (Keeling et al., 2010).

However, fully understanding ocean biogeochemical responses to deoxygenation is challenging owing to multiple biogeochemical feedbacks to low DO that are superimposed on physiochemical changes (Paulmier et al., 2011). In particular, both biological production of DO via gross primary production (GPP), and DO consumption via community respiration (CR), may change as the ocean warms and loses oxygen (Gregg et al., 2005; Behrenfeld et al., 2006; Bakun et al., 2010; Doney et al., 2012; Regaudie-de-Gioux and Duarte, 2012). Quantifying the net balance of these processes-and how they are arrayed along depth gradients of nutrients, light, temperature, and DO itself-is therefore essential. In the waters above OMZs, upwelled and regenerated nutrients stimulate high primary production at the surface, which provides ample organic matter to be respired as it sinks, reinforcing low oxygen waters below. If upwelling increases due to climate change (Bakun et al., 2010; Doney et al., 2012), or low oxygen/high nutrient areas shoal (Stramma et al., 2008; Gilly et al., 2013), then increased GPP could enhance CR and deoxygenation at depth. However, additional changes in nutrient cycling - and particularly the loss of available nitrogen (N) through anaerobic microbial activity in OMZs (Ward et al., 2009; Dalsgaard et al., 2012) — could directly affect rates of GPP and CR by altering the relative availability of nutrients (Elser et al., 2000; Moore et al., 2013). GPP and CR tend to be tightly coupled in many oceanic environments (Bograd and Lynn, 2001; Robinson and Williams, 2005), but GPP is obviously sensitive to light regimes, while both may be directly sensitive to temperature change (López-Urrutia et al., 2006; Regaudie-de-Gioux and Duarte, 2012). All of these issues are compounded by a lack of CR measurements in large portions of the world's oceans (del Giorgio and Williams, 2005; Robinson and Williams, 2005) including areas with naturally low DO conditions.

We used "marine lakes" as a natural experimental system for examining the environmental factors that dictate coupling and de-coupling between GPP and CR. Marine lakes formed as rising sea levels flooded inland basins, creating bodies of seawater surrounded by land (Hamner and Hamner, 1998; Dawson, 2006). Porous karst limestone allows varying connections between each marine lake with the outside sea, and the degree of connectivity is mostly dependent on a lake's distance inland (Hamner and Hamner, 1998; Colin, 2009). This varying level of connectivity, along with a lake's size and depth, dictate its degree of stratification (Hamner and Hamner, 1998). Consequently, marine lakes in Palau range from well-mixed holomictic lakeswhich contain marine fauna such as corals, sponges, and sharksto stratified, meromictic lakes (Colin, 2009). Across these different lakes, distinct gradients in DO (from fully oxygenated to anoxic conditions), temperature, light, the flux of organic material, the presence of key nutrients, and microbial community structure occur (Burnett et al., 1988; Hamner and Hamner, 1998; Meyerhof et al., 2016). In stratified meromictic lakes, the depths at which low DO values occur $(6-18 \mathrm{~m})$ are much shallower than in open ocean OMZs, and allow us to sample along oxygen gradients without spanning vast vertical and horizontal areas. This provides a natural, replicated experimental system where it is possible to study biogeochemical processes across multiple environmental gradients.

In Palau, we studied a gradient of sites ranging from a cove that lies within Palau's barrier reef lagoon; to two lakes that are well-connected to the surrounding ocean/lagoon, are wellmixed (holomictic), and are typically oligotrophic; to two lessconnected holomictic lakes; to three stratified meromictic lakes that vary in the depth of and vertical extent of anoxia (i.e., the depth of chemocline and total depth of lake). Across this cove, four holomictic lakes, and three meromictic lakes (Figure 1), we quantified GPP, CR, and net community production (NCP) at multiple depths-allowing us to identify variations in absolute rates and the relative balance of these processes. In order to quantify the effects of individual environmental variables that may be important in regulating GPP, CR, and NCP, two types of experimental manipulations were also conducted:

(1) Experimental additions of $\mathrm{N}$ and labile organic carbon (C) tested the degree to which GPP, CR, and NCP may be affected by $\mathrm{N}$ and $\mathrm{C}$ availability. We hypothesized that both GPP 


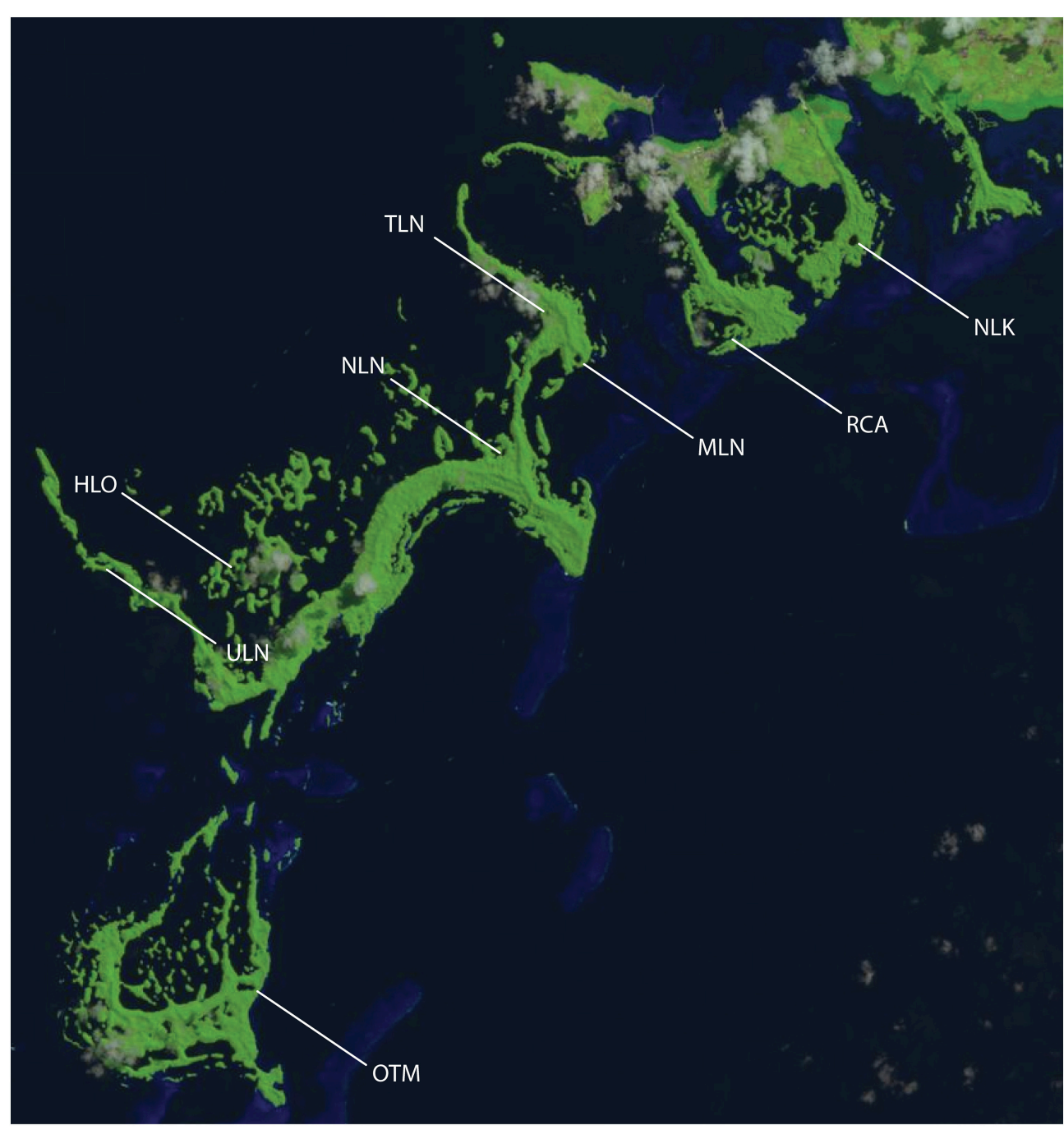

FIGURE 1 | Landsat image of Palau showing the location of sampling sites. Risong Cove (RCA) is a protected cove that is completely connected to the surrounding ocean; Heliofungia (HLO), Mekeald (MLN) are ocean-like holomictic lakes; Ngeruktabel (NLN), and Uet era Ngchas (ULN) are less-connected holomictic lakes; and Ngermeuangel Lake (NLK), Ongeim'l Tketau (OTM aka Jellyfish Lake), and T Lake (TLN) are stratified meromictic lakes.

and CR may be limited by $\mathrm{N}$ to varying degrees, leading to varying effects on NCP. In particular, we hypothesized that $\mathrm{N}$ removal in more deoxygenated lakes may lead to stronger $\mathrm{N}$ limitation of GPP and possible $\mathrm{N}$ limitation of $\mathrm{CR}$, while holomictic lakes may be P-limited and show no response to $\mathrm{N}$ additions. We expected that $\mathrm{C}$ additions would have no obvious effects on GPP, but would increase CR, particularly in holomictic lakes that lack available C. Finally, we hypothesized co-additions of $\mathrm{C}$ and $\mathrm{N}$ could produce interactive effects (e.g., through complementarity), leading to strong increases in CR.

(2) The effects of light and temperature on GPP, CR, and NCP were evaluated by "transplanting" bottles to new depths. We expected that changing light regimes would have obvious effects on GPP but little to no effect on CR, whereas CR would be more temperature sensitive than GPP.
Coupled with the natural gradients available in marine lakes, experimental manipulations allowed us to identify existing patterns and variations in GPP, CR, and NCP and the degree to which variations in $\mathrm{N}, \mathrm{C}$, light, and temperature may subsequently alter these patterns. We were able to elucidate some of the biogeochemical controls on metabolism in these tropical marine lakes, which may be applicable to other marine ecosystems.

\section{METHODS}

\section{Study Sites}

We examined one protected cove (Risong Cove; RCA) to provide a system that was completely connected to the ocean, for comparison to the marine lakes. Sampled holomictic lakes included Heliofungia (HLO), Mekeald (MLN), Ngeruktabel 
(NLN), and Uet era Ngchas (ULN). None of these lakes are stratified, but two are well-connected, ocean-like lakes with numerous marine fauna (HLO and MLN; Hamner and Hamner, 1998; Dawson and Hamner, 2005), whereas two are less-connected to the surrounding sea (NLN and ULN). However, salinities in all of these holomictic lakes are 32-35 ppt (Hamner and Hamner, 1998; Colin, 2009).

Among meromictic lakes, the depth at which stratification occurs differs between lakes, creating oxyclines of varying intensity (Table 1). We examined stratified meromictic lakes with the least extreme oxyclines, including Ngermeuangel Lake (abbreviated NLK), Ongeim'l Tketau (OTM aka Jellyfish Lake), and T Lake (TLN). Stratification in these lakes is driven by differences in salinity-and therefore density-with depth (Hamner et al., 1982; Hamner and Hamner, 1998). Surface waters are typically $25 \mathrm{ppt}$ in OTM and NLK and increase to 32-33 ppt at depth (Hamner and Hamner, 1998; Meyerhof et al., 2016). T Lake is "transitional" in that it periodically stratifies but is not permanently meromictic; it was stratified at the time of our sampling. Due to the lack of mixing and oxygen at depth, the concentration of reduced compounds increases greatly with depth in meromictic lakes, with hydrogen sulfide concentrations reaching $2500 \mu \mathrm{M}$ below $25 \mathrm{~m}$ in OTM (Hamner et al., 1982). However, each of the meromictic lakes possesses a distinct chemocline-an area of sharp increase in reduced compounds as oxygen reaches zero-at a unique depth. Chemocline depths are typically consistent over time in each lake (Hamner and Hamner, 1998).

\section{Temperature, Oxygen, and Nutrient Profiles}

Temperature and DO profiles were collected using a YSI ProODO (YSI Incorporated, Yellow Springs, OH, USA). The detection limit for DO was $2.8 \mu \mathrm{M}$. Light and temperature were collected for the duration of the incubations by $\mathrm{HOBO}$ Dataloggers UA-002-08 (Onset Computer Corporation, Bourne, MA, USA). Dissolved nutrient profiles were collected, and nutrient analyses were conducted both before and after all incubations. For these measurements, water samples were filtered through $0.22 \mu \mathrm{m}$ Durapore PVDF hydrophilic filters (Millipore, Billerica, MA, USA) and filtrate was collected in high density polyethylene bottles; samples were then frozen and subsequently processed via flow injection analysis at the University of California, Santa Barbara Marine Analytical Laboratory.

Samples were analyzed for ammonium $\left(\mathrm{NH}_{4}^{+}\right.$; UCSB MAL analytical method for $\mathrm{NH}_{4}^{+}$, see below; Diamond and Huberty, 1996), nitrite $\left(\mathrm{NO}_{2}^{-}\right.$; Environmental Protection Agency (EPA) Method 353.2, Schroeder, 1997), nitrate+nitrite $\left(\mathrm{NO}_{3}^{-}+\mathrm{NO}_{2}^{-}\right.$; EPA Method 353.2, Diamond, 1997), and phosphate $\left(\mathrm{PO}_{4}^{3-}\right.$; EPA Method 365.1, Huberty and Diamond, 1998), on a Lachat QuikChem, 8000 Flow Injection Analyzer (Hach Company, Loveland, CO, USA). For all assays, a mid-range check standard took place every 20 samples to verify the accuracy of the measurements, and samples that were detected outside of the standards' range were diluted 1:10 and reanalyzed. Detection limits were $0.10 \mu \mathrm{M}$ for $\mathrm{NH}_{4}^{+}, 0.10 \mu \mathrm{M}$ for $\mathrm{NO}_{2}^{-}, 0.20 \mu \mathrm{M}$ for $\mathrm{NO}_{3}^{-}+\mathrm{NO}_{2}^{-}$, and $0.10 \mu \mathrm{M}$ for $\mathrm{PO}_{4}^{3-}$. For $\mathrm{NH}_{4}^{+}$measurements, each sample was injected into a flowing carrier stream through an injection valve, and then merged with an alkaline solution stream; the produced $\mathrm{NH}_{3}$ was diffused through a hydrophobic,

TABLE 1 | Lake and experiment information.

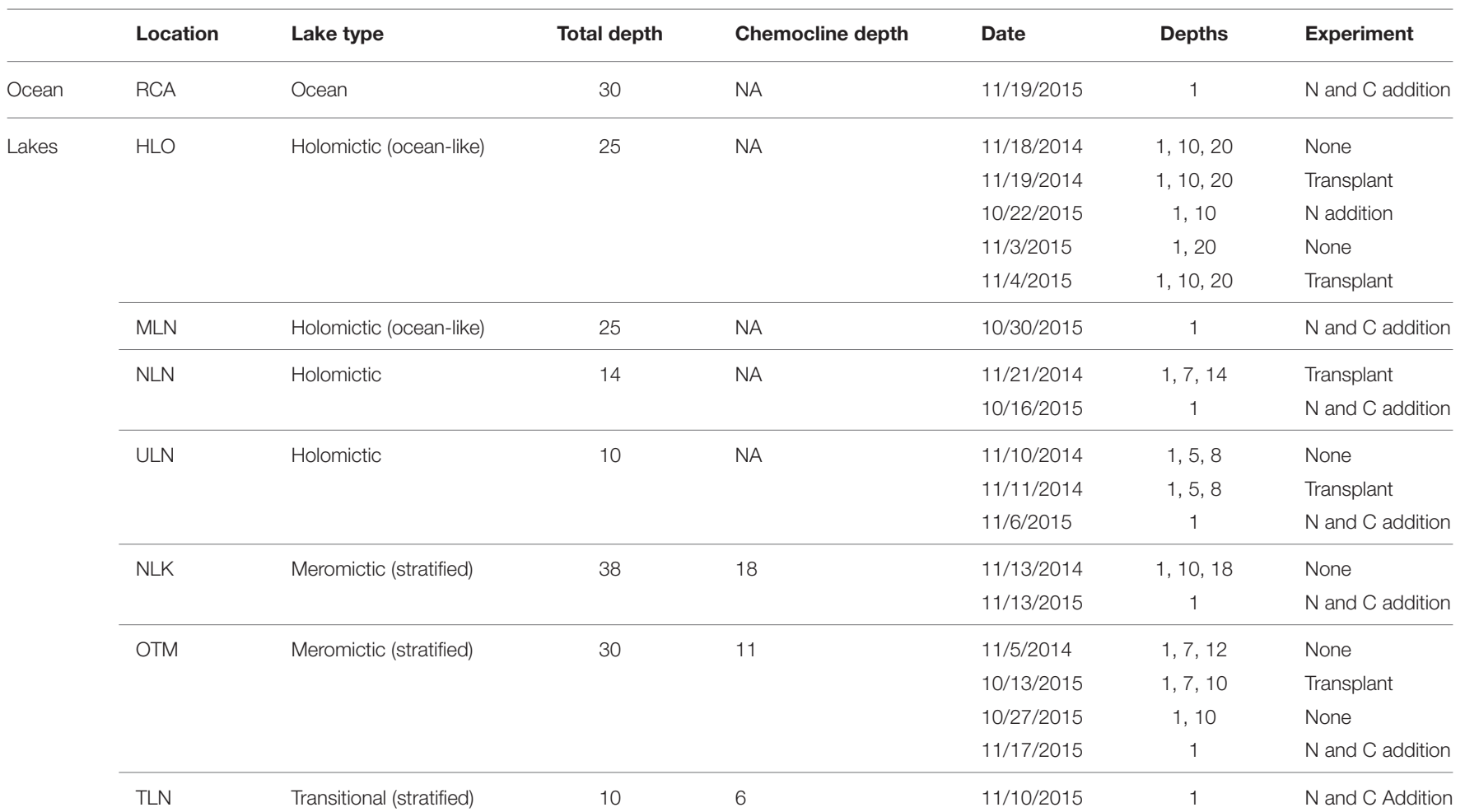


gas-permeable membrane into a recipient stream containing a $\mathrm{pH}$ indicator. Color change occurs in the indicator solution due to an increase in $\mathrm{pH}$, and the concentration of $\mathrm{NH}_{4}^{+}$ was determined spectrophotometrically based on absorption at $570 \mathrm{~nm}$.

$\mathrm{N}^{*}$ is a measure of $\mathrm{N}$ vs. phosphorus (P) availability based on the Redfield ratio (N:P = 16:1; Gruber and Sarmiento, 1997) and was calculated based on nutrient concentrations. The original formulation of $\mathrm{N}^{*}$ includes only oxidized dissolved $\mathrm{N}$ compounds, as dissolved $\mathrm{NH}_{4}^{+}$is typically found only at low concentrations in the open ocean (Gruber, 2008). However, dissolved $\mathrm{NH}_{4}^{+}$is detectable in Palau's marine lakes and reaches elevated levels below the chemocline in meromictic lakes (see below; Figure 3B). We therefore included $\mathrm{NH}_{4}^{+}$in the $\mathrm{N}$ pool in our revised $\mathrm{N}^{*}$ calculations according to Equation (1):

$$
\mathrm{N}^{*}=\left(\mathrm{NO}_{3}^{-}+\mathrm{NO}_{2}^{-}+\mathrm{NH}_{4}^{+}\right)-16^{*} \mathrm{PO}_{4}^{3-}
$$

\section{Production and Respiration Rate Measurements and Experiments}

Triplicate light and dark bottle incubations were used to measure NCP and CR throughout the oxic zone of holomictic and meromictic lakes, and into the low DO waters found in meromictic lakes, in 2014 and 2015 (Table 1). Depth profiles were collected in five out of seven lakes (HLO, NLN, ULN, NLK, and OTM), while measurements were made only in surface waters of MLN, TLN, and RCA. GPP was calculated by adding the mean absolute value of CR to the mean value of NCP (Morán et al., 2004). Measurements were made in $300 \mathrm{~mL}$ Wheaton BOD glass bottles filled to at least two times overflowing via slow laminar flow in order to exclude bubbles. For all lakes, bottles were incubated at the desired depth in each lake on a floating array constructed from cable and PVC pipe and attached to a surface buoy. The buoy was tied off to the sides of the lake to prevent drifting so that all incubations took place under in situ conditions. For the cove (RCA), it was not possible to anchor the array, and in situ incubations were mimicked by incubating bottles in the ocean at Coral Reef Research Foundation laboratory (Koror, Palau). The start time of all experiments was mid to late morning. All incubations were conducted for $24 \mathrm{~h}$ so that changes in CR with time of day would be integrated and eliminated (Williams, 2000).

During 2015, N and labile organic C additions were conducted for six lakes and RCA, while $\mathrm{N}$ additions were conducted at two depths in HLO (Table 1). All experiments were conducted in triplicate for both light and dark bottles. Water from $1 \mathrm{~m}$ depth was incubated at $1 \mathrm{~m}$ (in situ for lakes, and at the lab for RCA) as a control. Additionally, three treatments consisting of $\mathrm{NH}_{4}^{+}$ (5 $\mu \mathrm{M} \mathrm{NH} \mathrm{NH}_{4} \mathrm{Cl}$ ), sucrose $\left(100 \mu \mathrm{M} \mathrm{C}_{12} \mathrm{H}_{22} \mathrm{O}_{11}\right)$, and both $\mathrm{NH}_{4}^{+}$ + sucrose (at the above concentrations) were also incubated at $1 \mathrm{~m}$. At one lake (HLO), experiments were conducted at both $1 \mathrm{~m}$ and $10 \mathrm{~m}$, but only with controls and $\mathrm{NH}_{4}^{+}$additions (at the above concentration). $\mathrm{NH}_{4}^{+}$was used as an $\mathrm{N}$ source because the regeneration of $\mathrm{NH}_{4}^{+}$supports a large proportion of primary production throughout the ocean, and because several of the marine lakes have high concentrations of $\mathrm{NH}_{4}^{+}$at depth.

Reciprocal depth "transplants" were conducted for several lakes (HLO, NLN, ULN, OTM) during both 2014 and 2015.
Samples from $1 \mathrm{~m}$ and the deepest depth sampled in each lake were incubated at the opposite depth to assess the effect of light and temperature on NCP, CR, and GPP (Table 1). The deepest depth was near the lake bottom for holomictic lakes, while it was located just above the chemocline for meromictic lakes. All incubations were conducted in triplicate; however, oxygen contamination in two of the bottles from $10 \mathrm{~m}$ incubated at $1 \mathrm{~m}$ depth in OTM resulted in a single CR measurement for this treatment. It was therefore not possible to calculate standard errors for CR or for GPP.

All rates are reported in terms of mmol of $\mathrm{O}_{2}$ produced or consumed (rather than converted into $\mathrm{g}$ of $\mathrm{C}$ ) because (1) terrestrial inputs of organic matter may lead to non-Redfieldien consumption of oxygen and carbon, and (2) the amount of oxygen that is evolved during photosynthesis depends on the type of $\mathrm{N}$ utilized by phytoplankton, and (3) directly studying the cycling of oxygen is critically important in low-oxygen ecosystems.

\section{Statistical Analyses}

GPP, CR, and NCP rates from in situ measurements, experimental additions, or transplants were assessed via several statistical approaches. Linear and multiple regressions were performed on in situ rates with nutrients, the natural log of light, temperature, initial oxygen concentration, and site as explanatory variables (GPP was also used an explanatory variable for variation in CR). ANOVA was used to test the significance of the regressions. Linear regression was appropriate in all instances except for relating initial DO concentrations to CR, in which case a quadratic regression was performed. For experimental additions and transplants, Cohen's $d$ effect sizes were calculated for GPP, CR, and NCP. Cohen's $d$ demonstrates the strength of an experimental treatment by dividing the mean difference between treatments by the pooled standard deviation of the two means, and therefore shows the relative size and direction of change for each treatment and rate. For experimental additions and transplants, significant differences in NCP and CR were determined using ANOVA, and Tukey honestly significant difference (HSD) post-hoc tests were utilized to show which treatments/controls differed. For experimental transplants, linear and multiple regression were performed relating GPP, CR, and NCP to the natural log of light and to temperature in order to elucidate the effect of each on rates. ANOVA, linear regression, multiple regression, and best-fit models (as defined by the step function, which utilizes the Akaike Information Criterion) were carried out in the $\mathrm{R}$ statistical environment (RStudio Version 0.99.467). Figures were made with plotly and Adobe Illustrator. Figure 1 shows the location of sampling sites on a Landsat 8 Operational Land Imager (OLI) Natural Color image collected in June 2016 (https://landsat.usgs.gov/).

\section{RESULTS}

\section{Oxygen, Temperature, Nutrient, and $\mathrm{N}^{*}$ Profiles}

DO decreased with depth for all lake types and the cove, but the intensity of these gradients varied across lakes. For the oceanlike holomictic lakes (HLO and MLN) and the cove (RCA), 
DO decreased only slightly with increasing depth, and DO concentrations always remained above 180-200 $\mu \mathrm{M}$ (Figure 2A). In the less-connected holomictic lakes (NLN and ULN), DO decreased more substantially with depth, dipping below 175 $\mu \mathrm{M}$ but remaining above $140 \mu \mathrm{M}$. In the three meromictic lakes, DO concentrations decreased to undetectable levels $(<2.8$ $\mu \mathrm{M})$ at $18 \mathrm{~m}$ depth in NLK, $12 \mathrm{~m}$ in OTM, and $6 \mathrm{~m}$ in TLN. Temperature profiles showed that the holomictic lakes and RCA had very similar temperatures over space (depth) and time, while the meromictic lakes showed more variation (Figure 2B). The two deep meromictic lakes (NLK and OTM) showed the greatest depth variation in temperature. In NLK, temperature increased significantly with depth above the chemocline, before then decreasing with depth. In OTM, the decline in temperature took place around the depth at which DO reached undetectable levels, while the temperature decline took place several meters above this zone for NLK.

The stratified meromictic lakes also displayed the greatest change in $\mathrm{NH}_{4}^{+}$and $\mathrm{PO}_{4}^{3-}$, showing substantial increases with depth below the chemocline, whereas mixed homomictic lakes varied only slightly (Figures 3A,B; see also Hamner et al., 1982; Landing et al., 1991). In deeper portions of both OTM and NLK, $\mathrm{NH}_{4}^{+}$exceeded $100 \mu \mathrm{M}$ and $\mathrm{PO}_{4}^{3-}$ exceeded $5 \mu \mathrm{M} . \mathrm{NO}_{3}^{-}+\mathrm{NO}_{2}^{-}$ was more variable with depth in all the lakes, but tended to be higher in surface samples in meromictic lakes and increased with depth in holomicitc lakes (Figure 3C). Regardless of the specific lake or the depth of collection, $\mathrm{NO}_{3}^{-}+\mathrm{NO}_{2}^{-}$was always below
$3 \mu \mathrm{M} . \mathrm{N}^{*}$ is a proxy for the degree of $\mathrm{N}$ limitation or excess in marine ecosystems, and reflects underlying biogeochemical processes (Gruber and Sarmiento, 1997). In general, low oxygen marine ecosystems tend to be $\mathrm{N}$ depauperate $\left(\mathrm{N}^{*}<0\right)$ because denitrification and anammox can remove fixed forms of $\mathrm{N}$ under low oxygen conditions (Lam and Kuypers, 2011). OTM and TLN (meromictic lakes with shallower chemoclines) were typically $\mathrm{N}$-deficient $\left(\mathrm{N}^{*}<0\right)$ above the chemocline, while NLK (a meromictic lake with a fairly deep chemocline) typically had $\mathrm{N}^{*}$ values very close to 0 near the surface (Figure 3D). In all meromictic lakes, $\mathrm{N}^{*}$ increased with depth and was strongly positive below the chemocline due to the high concentrations of $\mathrm{NH}_{4}^{+}$(included in our formulation of $\mathrm{N}^{*}$ ). In contrast, $\mathrm{NH}_{4}^{+}$ concentrations were relatively constant and low in holomictic lakes. All holomictic lakes tended to have a slight excess of $\mathrm{N}$ based on our formulation of $\mathrm{N}^{*}$.

\section{In situ Rates of GPP, CR, and NCP}

Within and across lakes, we quantified GPP, CR, and NCP using in situ light/dark bottle incubations. We found high GPP in meromictic lakes, with all but two of the measurements exceeding $10 \mathrm{mmol} \mathrm{O}_{2} \mathrm{~m}^{-3} \mathrm{~d}^{-1}$ (Figure 4A). A wider range of rates was observed in holomictic lakes $(0.350 \pm 0.660-57.9 \pm 29.5 \mathrm{mmol}$ $\mathrm{O}_{2} \mathrm{~m}^{-3} \mathrm{~d}^{-1}$ ), with $60 \%$ of measurements lower than $10 \mathrm{mmol}$ $\mathrm{O}_{2} \mathrm{~m}^{-3} \mathrm{~d}^{-1}$. For holomictic lakes, GPP tended to be higher near the surface, declining by as much as $95.7 \%$ with depth (in HLO on Nov. 4, 2015). The more connected, ocean-like holomictic

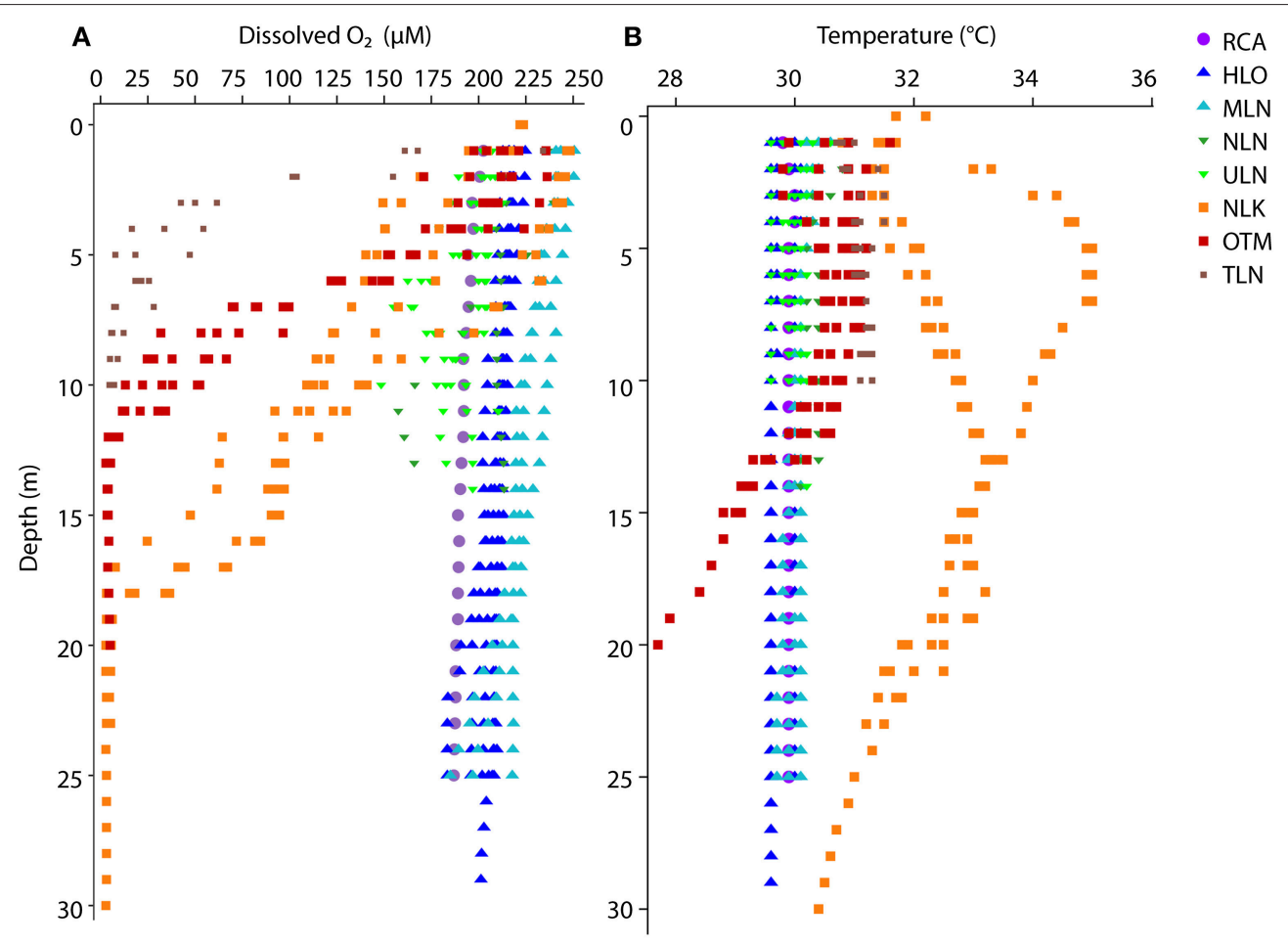

FIGURE 2 | Depth profiles of (A) dissolved oxygen and (B) temperature for each lake in which rates were measured. Colors denote the various lakes and the cove, and include all profiles collected; many of the lakes had very similar profiles on the different dates visited. HLO, MLN, NLN and ULN are holomictic lakes, whereas OTM, NLK, and TLN are meromictic lakes and show sharp decreases in oxygen with depth. 


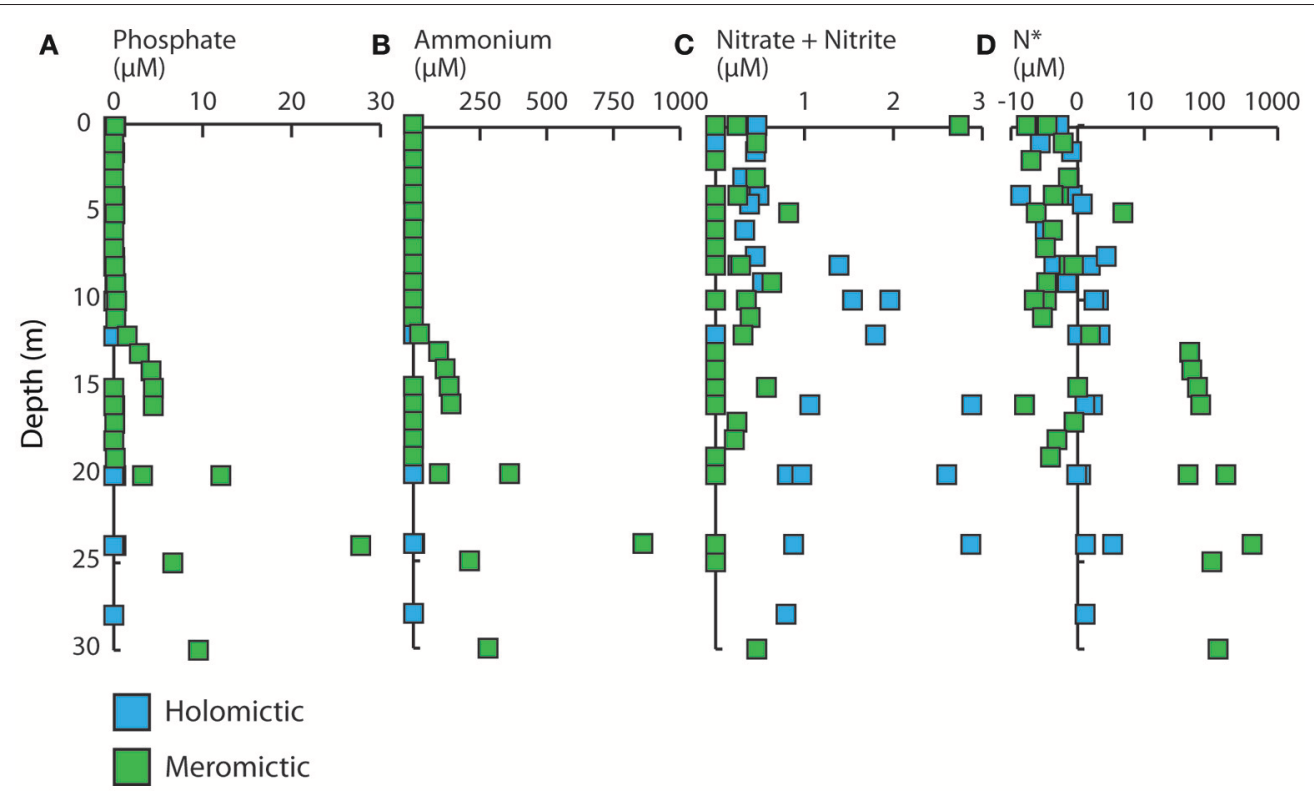

FIGURE 3 | Depth profiles of (A) $\mathrm{PO}_{4}^{3-}$, (B) $\mathrm{NH}_{4}^{+}$, (C) $\mathrm{NO}_{3}^{-}+\mathrm{NO}_{2}^{-}$, and (D) $N^{*}$ in holomictic and meromictic lakes. Colors denote the lake types. $N^{*}<0=$ $\mathrm{N}$-deficient, $N^{*}>0=$ P-deficient.

lakes were generally less productive than the more isolated holomictic lakes (ULN and NLN), which showed moderate but consistent decreases in GPP with depth (49.2-86.2\%). In contrast to holomictic lakes, GPP was often higher at depth in meromictic lakes, especially near the chemocline. For example, GPP was 60.6 $\pm 41.4 \mathrm{mmol} \mathrm{O}_{2} \mathrm{~m}^{-3} \mathrm{~d}^{-1}$ at $12 \mathrm{~m}$ depth in OTM on Nov. 05, 2014; this represents a $2620 \%$ increase from the surface rate and occurred at the approximate depth of the chemocline on that day. While there was variation in GPP within a site over time, this was minor compared to the variation between sites and with depth. Analyzing GPP and environmental data across all sites, dates, and depths, GPP significantly $(P<0.05)$ correlated with $\mathrm{PO}_{4}^{3-}$ concentration $\left(r^{2}=0.297\right)$, oxygen concentration $\left(r^{2}=\right.$ 0.185 ; Figure $5 \mathrm{~A})$, and $\mathrm{NH}_{4}^{+}$concentration $\left(r^{2}=0.102\right)$ - with GPP increasing as each of the nutrients increased, and decreasing at higher $\mathrm{O}_{2}$ concentrations. In multiple regression, the model that best explained variation in GPP was one that accounted for site, temperature, $\mathrm{PO}_{4}^{3-}$ concentration, $\mathrm{NO}_{2}^{-}$concentration, and $\mathrm{NO}_{3}^{-}$concentration $\left(r^{2}=0.782, P<0.001\right)$.

In contrast to GPP, CR was typically lower in magnitude and less variable with depth and across lakes (Figure 4B). For holomictic lakes, CR ranged from $0.196 \pm 2.18$ to $26.6 \pm 29.5$ mmol O$~_{2} \mathrm{~m}^{-3} \mathrm{~d}^{-1}$, with these values both observed at the surface in ULN. The ocean-like holomicitc lakes (HLO and MLN) tended to have lower CR rates, with 9 of the 14 measurements below $5 \mathrm{mmol} \mathrm{m}{ }^{-3} \mathrm{~d}^{-1}$ (data from MLN not shown). RCA behaved similarly to these lakes in terms of $\mathrm{CR}$, with a rate of $5.24 \pm 0.462$ $\mathrm{mmol} \mathrm{O}_{2} \mathrm{~m}^{-3} \mathrm{~d}^{-1}$ (data not shown). For meromictic lakes, CR ranged from undetectable levels to $53.6 \pm 19.3 \mathrm{mmol} \mathrm{O}_{2} \mathrm{~m}^{-3}$ $\mathrm{d}^{-1}$ and, similar to GPP, rates tended to increase with depth (up to $263 \%$ when the deepest depth was compared to the surface). However, the highest CR rates in meromictic lakes were observed a few meters above the chemocline at $7 \mathrm{~m}$ in OTM $(53.6 \pm 19.3$ $\mathrm{mmol} \mathrm{O}_{2} \mathrm{~m}^{-3} \mathrm{~d}^{-1}$ in 2014 and $48.2 \pm 11.2 \mathrm{mmol} \mathrm{O}_{2} \mathrm{~m}^{-3} \mathrm{~d}^{-1}$ in 2015). Like GPP, CR was significantly correlated with oxygen $\left(r^{2}=0.340\right)$; however, this relationship was nonlinear, with highest CR at intermediate oxygen concentrations (Figure 5B). When regressed linearly, CR was not significantly correlated with GPP, but was significantly positively correlated with the natural $\log$ of light $\left(r^{2}=0.156\right)$. In multiple regression, accounting for site, GPP, the natural log of light, $\mathrm{PO}_{4}^{3-}$ concentration, $\mathrm{NO}_{2}^{-}$concentration, and $\mathrm{NO}_{3}^{-}$concentration explained the most variation in CR across all sites, dates, and depths $\left(r^{2}=0.712\right)$.

As the data above indicate, most depths in most lakes were net autotrophic (i.e., NCP $>0 \mathrm{mmol} \mathrm{O}_{2} \mathrm{~m}^{-3} \mathrm{~d}^{-1}$; Figure 4C). This was particularly true for surface samples $(1 \mathrm{~m})$, which were almost uniformly autotrophic. For the ocean-like holomictic lakes (HLO and MLN), NCP ranged from $-5.69 \pm 1.98 \mathrm{mmol} \mathrm{O}_{2}$ $\mathrm{m}^{-3} \mathrm{~d}^{-1}$ (in MLN, data not shown) to $19.9 \pm 1.53 \mathrm{mmol} \mathrm{O}_{2} \mathrm{~m}^{-3}$ $\mathrm{d}^{-1}$, with both values observed at the surface. NCP in the more productive holomictic lakes (NLN and ULN) ranged from -9.85 \pm 1.7 to $31.3 \pm 1.15 \mathrm{mmol} \mathrm{O}_{2} \mathrm{~m}^{-3} \mathrm{~d}^{-1}$. NCP tended to decrease with increasing depth (by as much as $158 \%$ in HLO and $163 \%$ in ULN), with deeper samples becoming slightly heterotrophic in ULN and in HLO on certain dates. For meromictic lakes, $\mathrm{NCP}$ ranged from $-54.9 \pm 14.6$ to $36.5 \pm 17.7 \mathrm{mmol} \mathrm{O}_{2} \mathrm{~m}^{-3}$ $\mathrm{d}^{-1}$. In both NLK and OTM, the lowest and most heterotrophic NCP was observed several meters above the chemocline, while the depth sampled nearest the chemocline was autotrophic in each case. In both of these lakes, NCP was therefore positive at the surface, negative at mid-depth, and then strongly positive again near the chemocline. Across all lakes, NCP significantly positively correlated with $\mathrm{PO}_{4}^{3-}$ concentration $\left(r^{2}=0.114\right)$ and the natural $\log$ of light $\left(r^{2}=0.141\right)$. In multiple regression, 

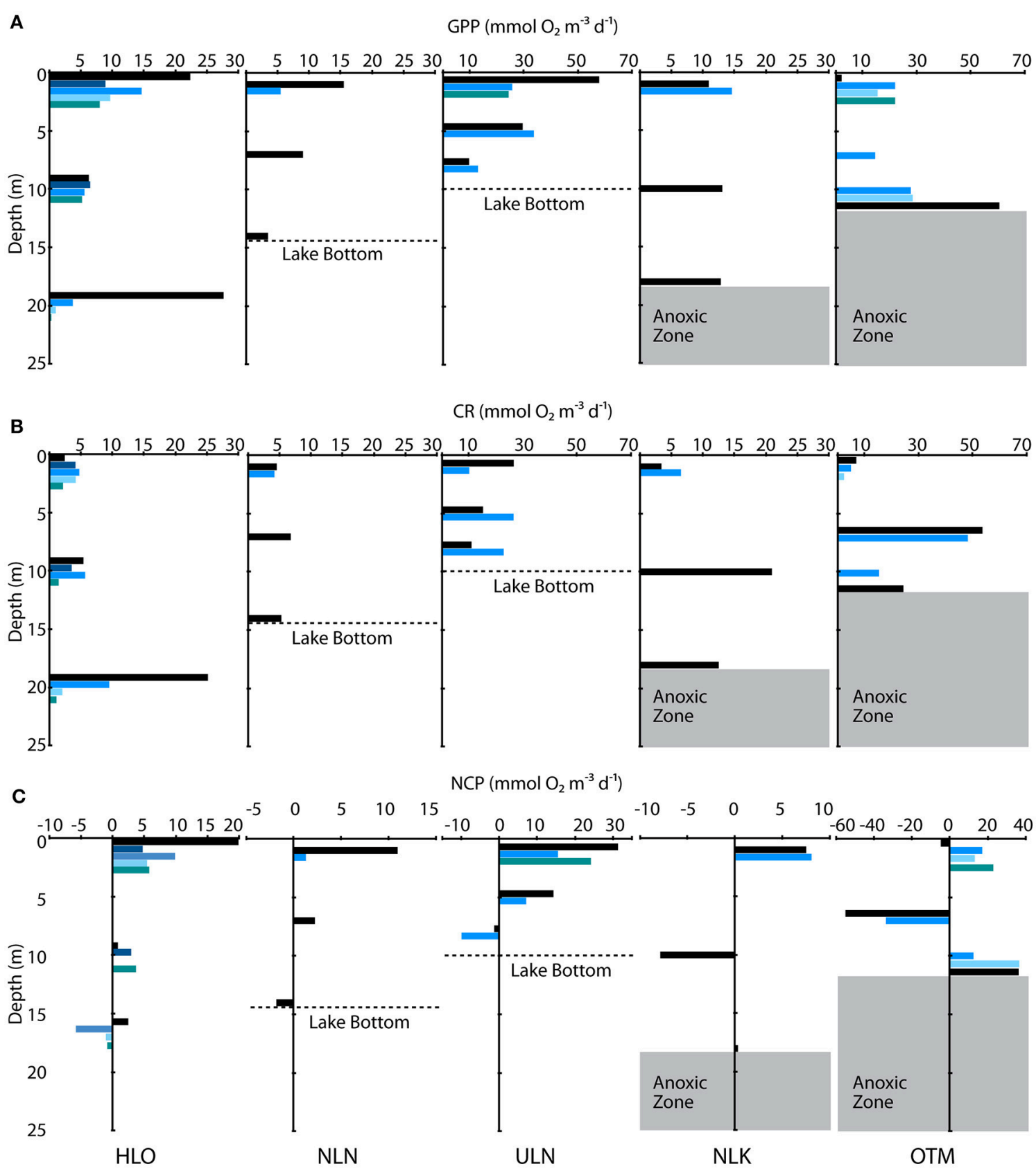

FIGURE 4 | Depth profiles of (A) GPP, (B) CR, and (C) NCP collected in five lakes listed at the bottom of the figure. Colored bars indicate different measurement periods in 2014 and 2015. Dashed lines denote the lake bottom in NLN and ULN, and the gray shaded area shows the anoxic zone in NLK and OTM. GPP and CR data are plotted on the same axes for each lake, but note the differences between GPP and CR axes for ULN and OTM compared with the other lakes. NCP axes differ across all lakes.

variation in NCP was best-explained by site, the natural $\log$ of light, $\mathrm{PO}_{4}^{3-}$ concentration, $\mathrm{NO}_{2}^{-}$concentration, and $\mathrm{NO}_{3}^{-}$ concentration $\left(r^{2}=0.832\right)$.

\section{$\mathbf{N}$ and $\mathbf{C}$ Additions}

Experimental additions of $\mathrm{NH}_{4}^{+}(5 \mu \mathrm{M})$, labile $\mathrm{C}(100 \mu \mathrm{M})$, and both $\mathrm{N}$ and $\mathrm{C}$, had significant effects on GPP, CR, and NCP (Figure 6). Responses varied between treatments, sites, and rate, with Cohen's $d$ demonstrating the direction and magnitude of each effect. As we hypothesized, $\mathrm{C}$ addition alone had very little effect on GPP, with Cohen's $d$ only increasing above 2 for RCA (Figure 7A). TLN actually had a slightly negative effect size following $\mathrm{C}$ addition (-0.409), but all other values were slightly positive. In contrast to $\mathrm{C}$ addition, $\mathrm{N}$ addition had much larger effects on GPP: Cohen's $d$-values that ranged from slightly negative (RCA, HLO, MLN, and TLN) to significantly positive 

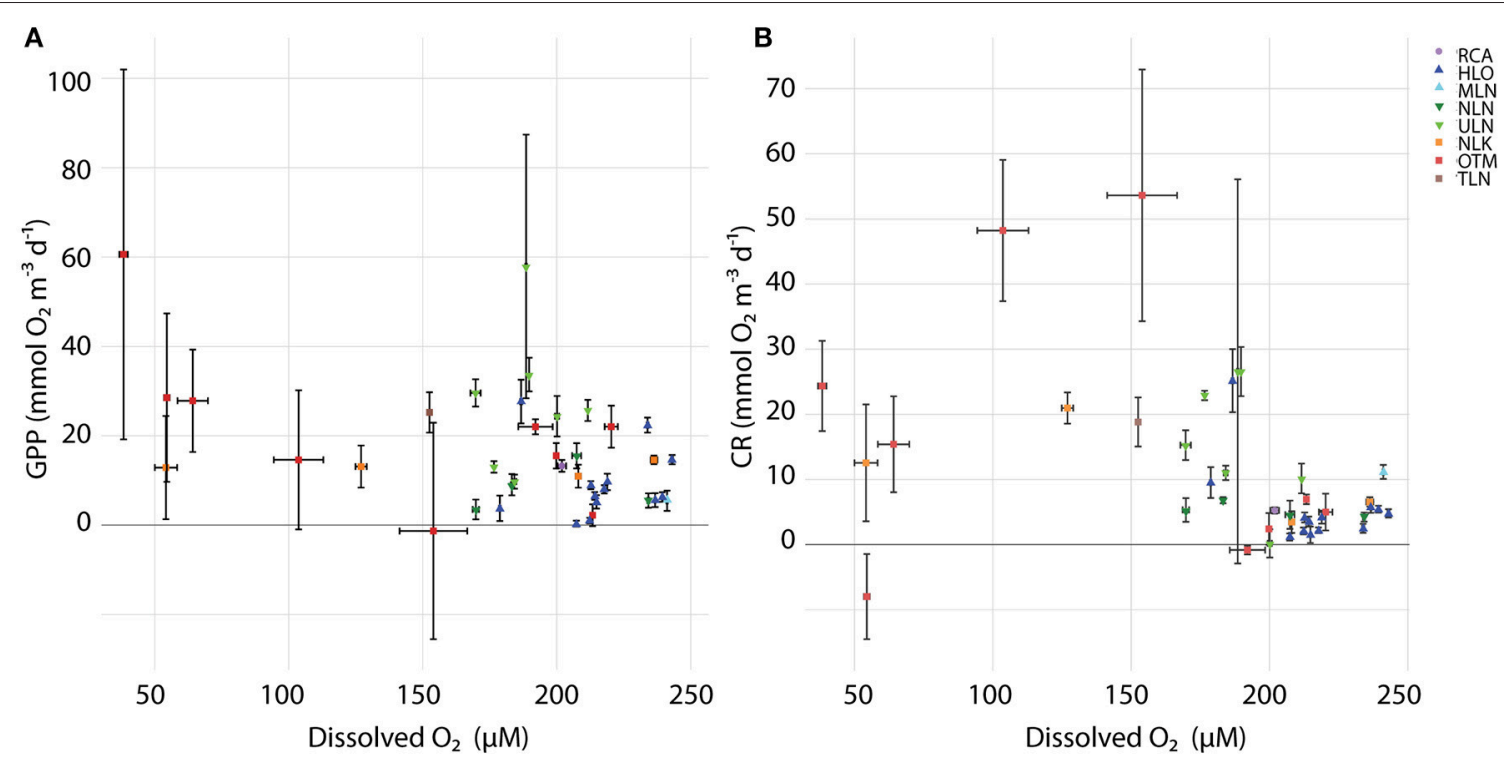

FIGURE 5 | Relationships between oxygen concentration against (A) GPP and (B) CR. Error bars denote standard error and colors denote different sampling times.

in NLN, ULN, NLK, and OTM. In general, the highest rates of GPP for both controls and following experimental addition were observed where $\mathrm{N}^{*}<0$. Adding both $\mathrm{C}$ and $\mathrm{N}$ produced the largest change in GPP in RCA, MLN, NLN, and NLK-with NLK showing a Cohen's $d$ of 13.5 .

CR rates were typically more responsive than GPP to additions (Figures 6B, 7B). Adding N caused CR to significantly increase in NLN and NLK ( $p=0.012$ and 0.014 , respectively) with Cohen's $d<4$. Labile $\mathrm{C}$ additions caused CR to significantly increase in RCA and ULN ( $p<0.001$ and 0.025 , respectively), nearly significantly increase in NLN $(p=0.056)$, and significantly decrease in MLN ( $p=0.003)$. An effect size larger than 10 was observed from $\mathrm{C}$ additions in RCA. $\mathrm{C}$ and $\mathrm{N}$ co-additions resulted in a significant several-fold increase in $\mathrm{CR}$ at all sites $(p<0.001-0.048)$ but MLN, with the highest Cohen's $d$ values observed in RCA and OTM (60.4 and 45.5, respectively; Figure 7B). The highest overall values were observed following $C$ and $\mathrm{N}$ co-addition in the meromictic lakes-especially those with chemoclines close to the surface $\left(85.3 \pm 9.43 \mathrm{mmol} \mathrm{O}_{2} \mathrm{~m}^{-3} \mathrm{~d}^{-1}\right.$ in TLN and $91.5 \pm 1.51 \mathrm{mmol} \mathrm{O}_{2} \mathrm{~m}^{-3} \mathrm{~d}^{-1}$ in OTM) - while RCA and the less-connected holomictic lakes (i.e., NLN and ULN) all had CR values above $40 \mathrm{mmol} \mathrm{O}_{2} \mathrm{~m}^{-3} \mathrm{~d}^{-1}$ following $\mathrm{C}$ and $\mathrm{N}$ addition.

As the results above indicate, co-additions of $\mathrm{C}$ and $\mathrm{N}$ yielded the greatest overall changes in NCP (Figure 6C). NCP frequently switched from net autotrophy to net heterotrophy $(\mathrm{NCP}<0$ mmol $\mathrm{O}_{2} \mathrm{~m}^{-3} \mathrm{~d}^{-1}$ ), with five of the seven treatments that were subjected $\mathrm{C}$ and $\mathrm{N}$ co-additions becoming heterotrophic, and displaying Cohen's $d$-values of -2.02 to -9.03 (Figure 7C). The largest changes in metabolic state were observed in OTM and TLN, followed by NLN and ULN. Neither MLN nor NLK changed metabolic state following $\mathrm{C}$ and $\mathrm{N}$ addition, but each displayed an increase in NCP, with NLK showing a significant increase in NCP. All changes in metabolic state were significant ( $p<0.001-0.006)$, except for ULN $(p=0.069)$. C addition alone caused a change in metabolic state on two occasions, with RCA and TLN each switching from net autotrophy to net heterotrophy ( $p<0.001$ and 0.022 ; Cohen's $d$ of -8.76 and -1.87$)$. None of the other lakes had significant changes in NCP following C additions. Adding $\mathrm{NH}_{4}^{+}$alone significantly affected NCP in NLK, producing a significant increase in autotrophy in that layer of the lake $(p=0.015)$ with an effect size of 2.79. Because lakes and depths with lower $\mathrm{N}^{*}$ values had the highest $\mathrm{CR}$ following $\mathrm{C}$ and $\mathrm{N}$ addition, these lakes and depths also yielded the most heterotrophic systems following $\mathrm{C}$ and $\mathrm{N}$ addition.

Nutrient concentration measurements following experimental additions and $24 \mathrm{~h}$ incubations showed relatively few differences-however, this included bottles to which $5 \mu \mathrm{M}$ $\mathrm{NH}_{4}^{+}$was added, alone or in combination with $\mathrm{C}$ (Table 2). $\mathrm{NH}_{4}^{+}$concentrations were elevated in dark bottles following $\mathrm{N}$ addition $(p<0.05)$, but $\mathrm{NH}_{4}^{+}$concentrations were similar across controls, $\mathrm{C}$ additions, and $\mathrm{N}$ and $\mathrm{C}$ co-additions.

\section{Transplant Rate Measurements}

We also experimentally quantified the effects of light and temperature on GPP, CR, and NCP by incubating bottles at different depths (although the particular lake and nutrient concentrations also played roles in the observed rates). As expected, GPP increased as the water was moved closer to the surface-the rate actually surpassed the in situ rates in some cases (e.g., HLO in 2014 and ULN) - and it decreased as water was moved to deeper depths (Figure 8A). Following incubation at a new depth (which depended on overall lake depth and whether a chemocline present), both light and dark bottles tended to remain significantly different from the control groups-i.e., rates incubated at a new depth differed from both the original depth 

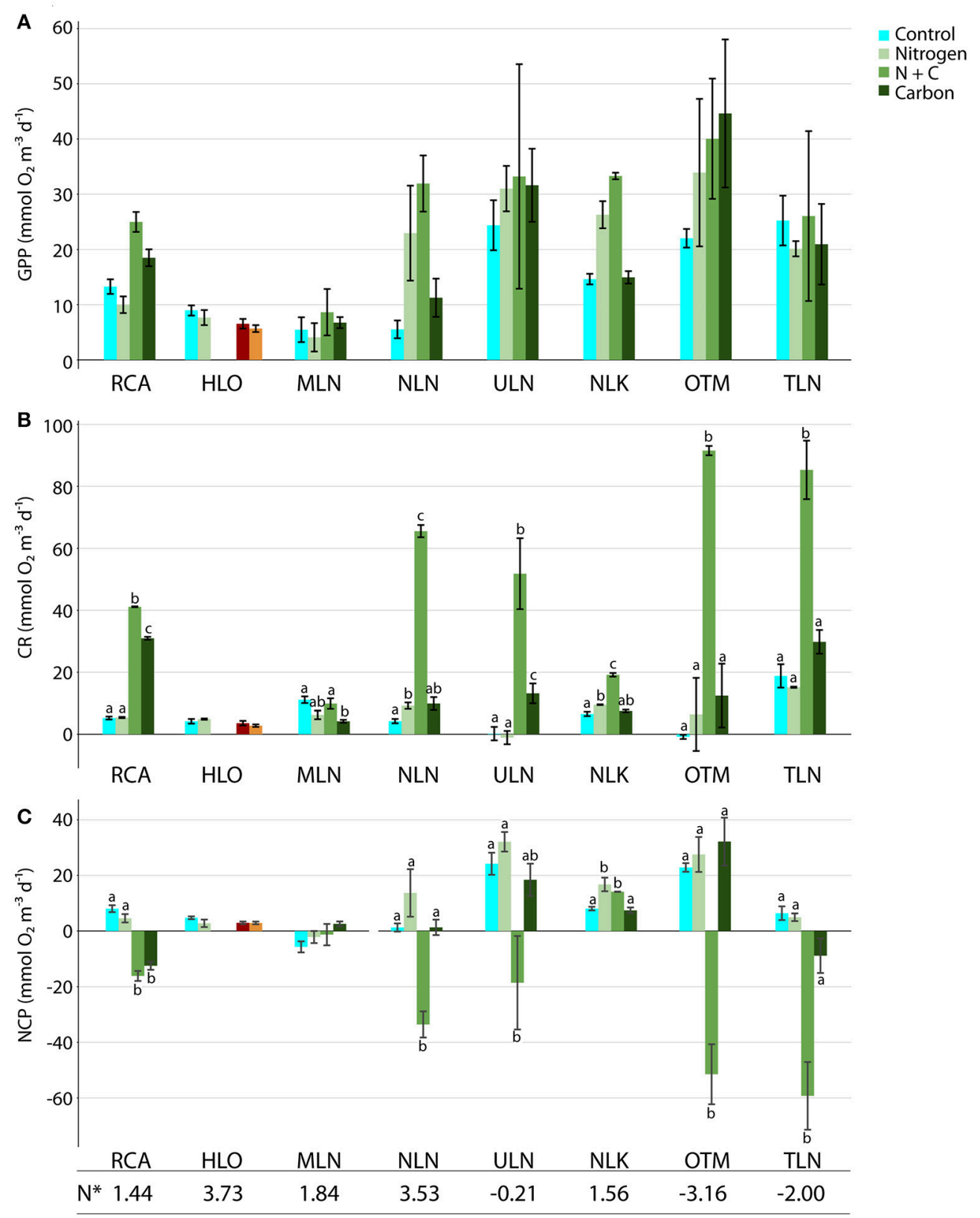

FIGURE 6 | Effects of experimental additions of nitrogen, carbon, and nitrogen + carbon on (A) GPP, (B) CR, and (C) NCP. Colors denote the treatments and error bars denote standard error. (Orange and red bars denote a second N addition experiment conducted at $10 \mathrm{~m}$ depth in HLO.) Letters show Tukey HSD test results for each lake-i.e., whether additions are different from one another and/or the control. $N^{\star}$ values are labeled below each lake.

and the depth they were transplanted to. However, almost all the transplanted bottles became more similar (for both light and dark bottles) to the water at the depth they were incubated (Figures 8B,C).

Cohen's $d$-values were generally lower for CR rates than for GPP (data not shown), with the greatest changes observed in ULN-as CR increased in surface water that was moved down $(d=3.69)$-and in HLO-as CR in deep water that was incubated at the surface decreased $(d=-2.45)$ NCP also changed the most with transplantation in ULN and in HLO. These transplants modify light and temperature, and GPP was significantly correlated with the natural log of light when both controls and transplants were assessed together ( $p$ $\left.=0.031, r^{2}=0.292\right)$. However, the best multiple regression model for predicting GPP accounted for site, temperature, $\mathrm{NO}_{3}^{-}$ concentration, and $\mathrm{NH}_{4}^{+}$concentration $\left(p=0.090, r^{2}=\right.$ 0.718). CR did not show strong responses to transplantation, but regression analysis showed that CR was negatively correlated 

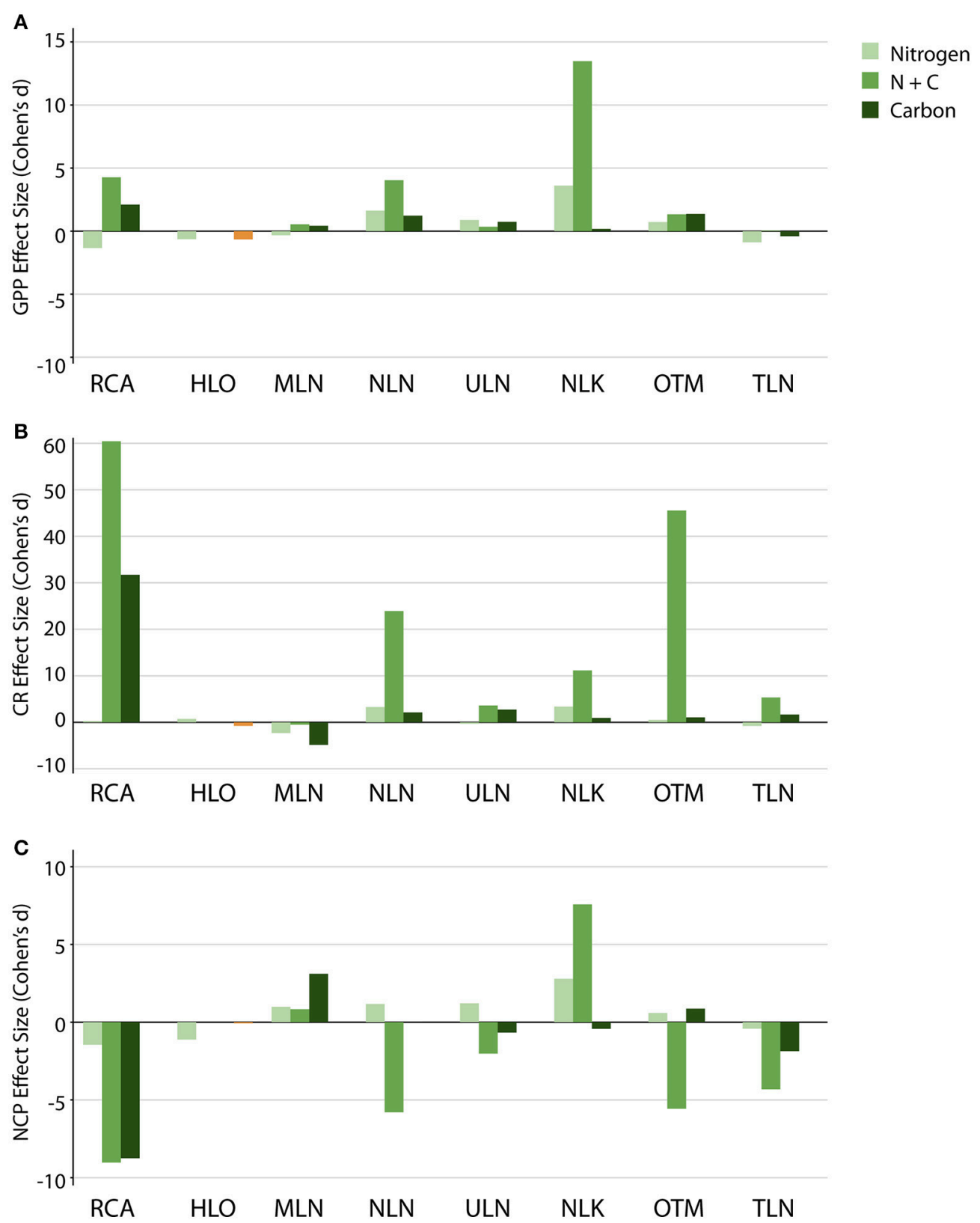

FIGURE 7 | Effect sizes (Cohen's d) for experimental additions. Effect sizes are shown for additions of nitrogen, carbon, and nitrogen + carbon on (A) GPP, (B) $\mathrm{CR}$, and (C) NCP. Colors denote treatment (orange and red bars denote a second N addition experiment conducted at $10 \mathrm{~m}$ depth in HLO).

with temperature across all the lakes for transplanted bottles $(p=$ $\left.0.013, r^{2}=0.365\right)$. CR also correlated positively with GPP ( $p=$ $\left.0.040, r^{2}=0.215\right)$.

\section{DISCUSSION}

The marine lakes of Palau serve as a natural experimental system in which variations in GPP, CR, and NCP along strong environmental gradients can be assessed. We studied a gradient of sites ranging from a cove and lakes that exchange water with the oligotrophic Western Pacific, to stratified meromicitc lakes that resemble other low-oxygen marine ecosystems. Differences among sites are reflected in their biogeochemical properties, including the presence of anoxia at $18 \mathrm{~m}$ depth in NLK, $12 \mathrm{~m}$ depth in OTM, and $6 \mathrm{~m}$ depth in TLN (Figure 2A), as well as accompanying variability in nutrient concentrations (Figure 3). GPP, CR, and NCP showed predictable patterns with depth and in relation to variations in DO, nutrients, temperature and light with depth and across lakes. Coupled with the natural gradients available in marine lakes, experimental manipulations allowed us to test how changes 
TABLE 2 | Average nutrient concentrations in different treatments following experimental additions of $\mathrm{NH}_{4}^{+}\left(5 \mu \mathrm{M} \mathrm{NH}_{4} \mathrm{Cl}\right), \mathrm{C}(100 \mu \mathrm{M})$, and both $\mathbf{N}+\mathbf{C}$.

\begin{tabular}{ccccc}
\hline Experimental treatment & $\mathbf{N H}_{\mathbf{4}}^{+}(\boldsymbol{\mu} \mathbf{M})$ & $\mathbf{N O}_{\mathbf{2}}^{-}+\mathbf{N O}_{\mathbf{3}}^{-}(\mu \mathbf{M})$ & $\mathbf{P O}_{\mathbf{4}}^{3-}(\mu \mathbf{M})$ \\
\hline \multirow{3}{*}{ Light bottles } & Control & $0.56 \pm 0.31$ & $1.23 \pm 0.16$ & $0.07 \pm 0.03$ \\
& $\mathrm{~N}+\mathrm{C}$ & $1.84 \pm 1.85$ & $1.21 \pm 0.20$ & $0.06 \pm 0.02$ \\
& $\mathrm{C}$ & $1.94 \pm 0.45$ & $1.13 \pm 0.08$ & $0.01 \pm 0.01$ \\
Dark bottles & $\mathrm{N}$ & $0.82 \pm 0.15$ & $0.07 \pm 0.01$ \\
\hline & $\mathrm{N}+\mathrm{C}$ & $0.96 \pm 0.29$ & $1.12 \pm 0.15$ & $0 \pm 0$ \\
& $\mathrm{C}$ & $0.57 \pm 0.11$ & $0.87 \pm 0.13$ & $0.04 \pm 0.01$ \\
\hline
\end{tabular}

in $\mathrm{N}, \mathrm{C}$, light, and temperature may subsequently alter these patterns.

\section{Patterns in GPP, CR, and NCP within and Across Marine Lakes}

The holomictic lakes in this study displayed depth patterns in GPP, CR, and NCP that are similar to those that observed throughout much of the ocean. GPP was higher near the surface and declined with depth, while CR was less variable with depth, resulting in net autotrophy near the surface, shifting to near balance or heterotrophic conditions at depth. While the shape of depth profiles were similar to the open ocean (e.g., compare with rates observed along the Atlantic Meridional Transect; Serret et al., 2001), the rate magnitudes in several marine lakes were on the high end of those observed in other marine systems. For example, ULN behaved like a holomictic lake in terms of the metabolic depth profile, but had absolute rates more similar to the meromictic lakes.

Meromictic lakes generally displayed higher overall rates for both GPP and CR that were comparable to other highnutrient marine ecosystems (Blight et al., 1995; Serret et al., 2001; Gist et al., 2009). Interestingly, the meromictic lakes NLK and OTM displayed consistent depth patterns in GPP, CR, and NCP that differed from those in the holomictic lakes: GPP typically exceeded CR at $1 \mathrm{~m}$ depth, as well as near the chemocline $(18 \mathrm{~m}$ in NLK and 10-12 $\mathrm{m}$ in OTM), leading to net autotrophy; CR was greater than GPP in between these depth horizons, leading to net heterotrophy. In NLK, this variation with depth was driven by variations in CR, as GPP was relatively constant with depth. In OTM, variations in both GPP and CR produced these patterns with depth. We attribute net heterotrophy at mid-depths $(10 \mathrm{~m}$ in NLK and $7 \mathrm{~m}$ in OTM) to microbial consumption of sinking organic matter; however, heterotrophy was the exception rather than the rule in marine lakes, as most depths and lakes that were sampled were autotrophic (Figure 4). This suggests that despite the presence of productive forested watersheds surrounding marine lakes (a major difference from the open ocean), terrestrial organic material does not play a large role in their metabolism and C cycle. Previous work in OTM supports this idea. Orem et al. (1991) found that although the sediment of OTM was approximately $50 \%$ organic matter, it was dominated by vascular plant material (66-91\%), suggesting that allochthonus organic matter is not readily metabolized within the lake. Lake microbial communities are also dominated by common marine bacteria ill-equipped to consume terrestrial organic material (Meyerhof et al., 2016).

The peak in GPP near the chemocline in OTM is likely sustained by upward diffusion of nutrients due to the sharp gradient present in this lake. However, OTM is also unique in that it is a "jellyfish lake" that harbors millions of medusa; the activity of these organisms could lead to biomixing that transfers nutrients into the upper water column (Katija and Dabiri, 2009; Breitburg et al., 2010). Our results from OTM are in line with Hamner et al. (1982), who found similarly high NCP values in the oxygenated surface zone of OTM $\left(0.336 \mathrm{~mol} \mathrm{O} \mathrm{O}^{-2}\right.$ $\mathrm{d}^{-1}$ or $30.6 \mathrm{mmol} \mathrm{O}_{2} \mathrm{~m}^{-3} \mathrm{~d}^{-1}$ assuming a chemocline of 11 $\mathrm{m})$. In both NLK and OTM, low CR and high NCP near the chemocline suggest a substantial flux of organic matter from the upper portion of the lake into deeper layers. However, Lyons et al. (1996) estimated that in OTM only 4\% of autochthonous organic matter is deposited on the lake bottom, with vertical stratification slowing the decent of phytoplankton-derived organic matter.

Most organic matter produced in the upper oxygenated zone is therefore remineralized in the lower layers of the lake (either in the suboxic zone or the anoxic zone). Low oxygen would not necessarily halt aerobic respiration, as CR has been directly measured in extremely low oxygen concentrations (Tiano et al., 2014). Particulate organic matter has also been observed to be rapidly recycled in the suboxic portions of the Black Sea (Karl and Knauer, 1991), and aerobic remineralization accounted for $\sim 45-100 \%$ of the organic matter that was degraded in the Eastern Tropical South Pacific OMZ (Kalvelage et al., 2015). Aerobic and anaerobic metabolism of sinking organic matter regenerates nutrients, and may create a positive feedback as remineralized nutrients fluxed upward further stimulate GPP. This phenomenon has been observed in OMZs (Karstensen et al., 2008; Deutsch et al., 2011), but is particularly clear in these meromictic marine lakes given the sharp nutrient gradients and high rates of GPP and CR.

\section{Effects of N and C on GPP, CR, and NCP in Experimental Additions}

As the results above indicate, GPP, CR, and NCP rates are tightly linked to nutrient and DO concentrations within and across marine lakes. We analyzed patterns in GPP, CR, and NCP in relation to natural nutrient, oxygen, temperature, and light gradients using regression. Observational measurements within and across the lakes demonstrate the effect of nutrients on these processes because holomictic lakes are well-mixed, with lower concentrations of nutrients, while meromictic lakes are stratified, with much higher concentrations of nutrients (especially below the chemocline). GPP and CR generally increased from oceanlike lakes to deoxygenated meromictic lakes (Figures 4, 6); regression analyses showed that GPP was positively correlated with several nutrients (independently and in multiple regression) while CR was related to nutrients during multiple regression. We further tested the effects of $\mathrm{N}$, as well as organic $\mathrm{C}$, using 


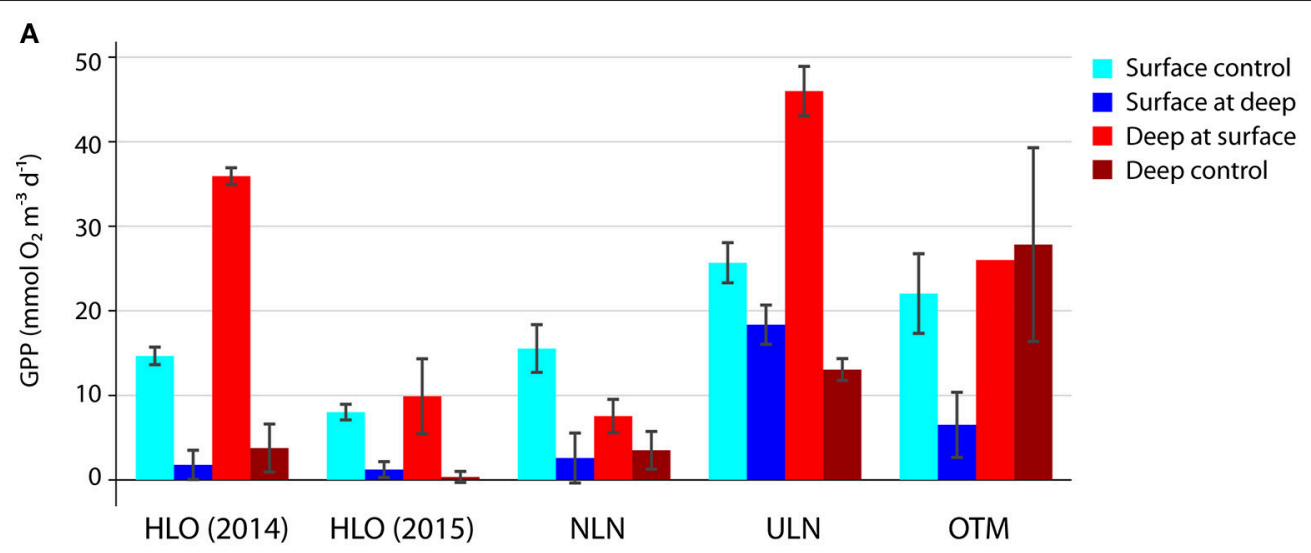

B

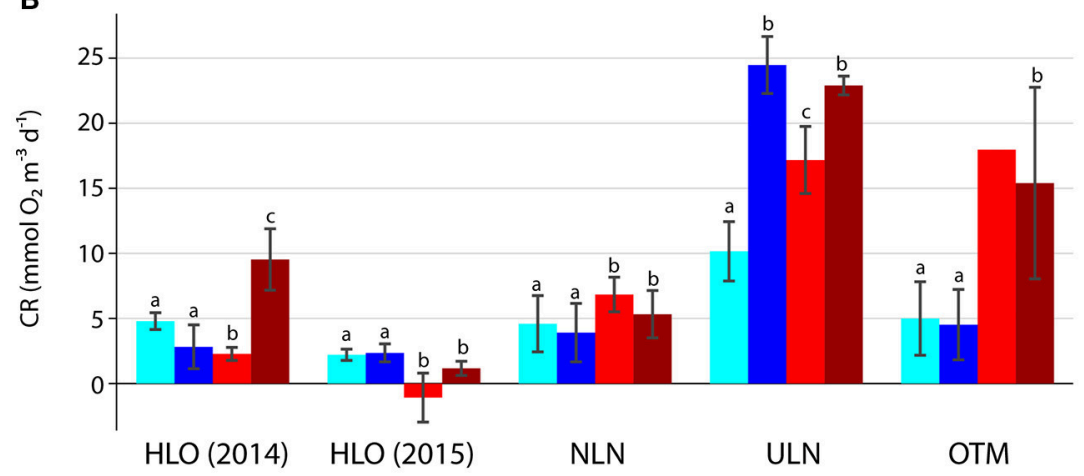

C

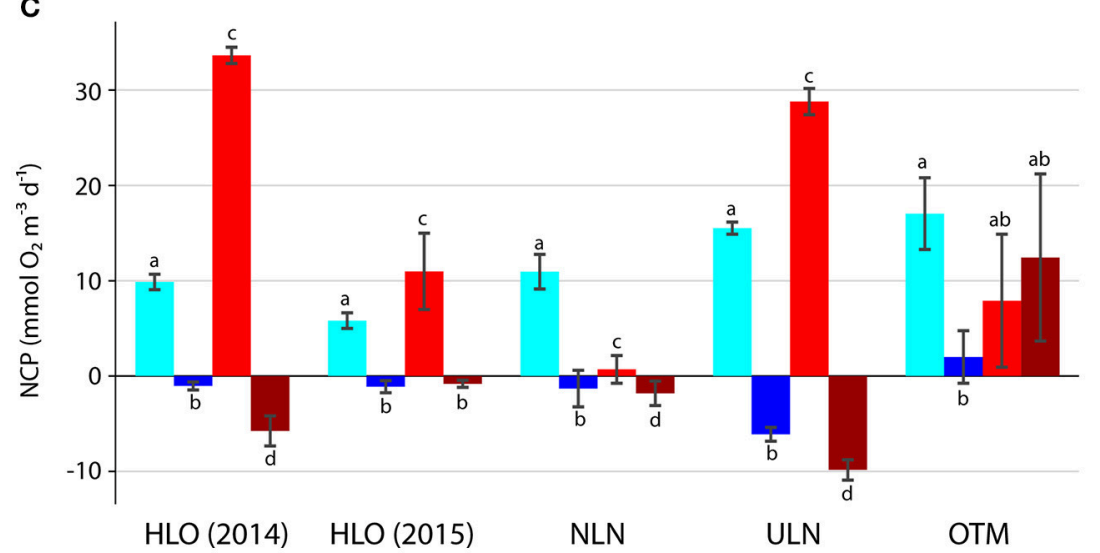

FIGURE 8 | Effect of depth transplants on (A) GPP, (B) CR, and (C) NCP. Colors denote the treatments and error bars denote standard error. Error bars are not shown for OTM deep at surface CR and GPP because oxygen contamination resulted in only a single valid CR measurement. Letters show Tukey HSD test results for each lake-i.e., whether additions are different from one another and/or the controls.

addition experiments that provided additional insight into how $\mathrm{N}$ and $\mathrm{C}$ influence GPP and CR. One of our hypotheses was that $\mathrm{N}$ removal in stratified, deoxygenated meromictic lakes may lead to $\mathrm{N}$ limitation of GPP and/or CR, while holomictic lakes may be $\mathrm{P}$-limited and show no response to $\mathrm{N}$ additions. We would expect $\mathrm{N}$-limitation to occur in low-oxygen environments because $\mathrm{N}$ is removed through anaerobic activity (Francis et al., 2007; Ward et al., 2009), leading to $\mathrm{N}$ deficits relative to $\mathrm{P}$ (Beman et al., 2005).
Additions of $\mathrm{N}$ alone increased GPP in the holomictic lakes NLN and ULN, and the meromictic lakes NLK and OTM, confirming our hypothesis for these lakes (Figures 6, 7). However, TLN had a slightly negative $\mathrm{N}^{*}$-value and GPP did not respond to $\mathrm{N}$ alone-indicating that either phytoplankton may require less $\mathrm{N}$ than the typical Redfield ratio dictates (N:P::16:1; Martiny et al., 2013), or that they utilize additional sources of N. For example, Bronk et al. (2007) outlined how the dissolved organic nitrogen pool is a possible $\mathrm{N}$ source for phytoplankton. 
As expected, $\mathrm{C}$ addition alone had little effect on GPP in most lakes, while co-additions of $\mathrm{N}$ and $\mathrm{C}$ showed similar GPP responses to additions of $\mathrm{N}$ alone. The only exception was RCA, where $\mathrm{N}$ and $\mathrm{C}$ increased GPP, while $\mathrm{N}$ alone had no effect.

In contrast to GPP, CR rates responded strongly to $\mathrm{N}$ additions, $\mathrm{C}$ additions, and particularly to combined $\mathrm{N}$ and $\mathrm{C}$ additions. Both NLN and NLK had heterotrophic communities that were stimulated by $\mathrm{N}$ addition, resulting in significantly higher CR. However, the effects of $\mathrm{N}$ alone were overshadowed by the synergistic effects of adding both $\mathrm{N}$ and C. All lakes but MLN showed sharp increases in $\mathrm{CR}$ following $\mathrm{N}$ and $\mathrm{C}$ co-addition. In nearly all cases where both $\mathrm{N}$ and $\mathrm{C}$ were added, CR increased to such a degree that the system became heterotrophic-i.e., CR increased much more than GPP (Figure 6). In general, these responses were strong in meromictic lakes (with the exception of NLK) compared with holomictic lakes, and in the less connected holomictic lakes (NLN and ULN) compared with the oceanlike lakes (HLO and MLN). In the lakes that did not undergo a metabolic shift in NCP (MLN and NLK), NLK showed an increase in CR in tandem with an increase in GPP, resulting in overall increased NCP. MLN showed a significant decrease in $\mathrm{CR}$ following addition of $\mathrm{C}$ alone, but no significant response to $\mathrm{N}$ or $\mathrm{N}$ and $\mathrm{C}$; $\mathrm{NCP}$ did not change significantly and all values were close to 0 . Finally, $\mathrm{N}$ and $\mathrm{C}$ additions increased $\mathrm{CR}$ far more than addition of $\mathrm{N}$ or addition of $\mathrm{C}$ alone (Figure 6), and the response was more than additive (Figure 7), indicating that the combination of $\mathrm{N}$ and $\mathrm{C}$ had synergistic effects on $\mathrm{CR}$. These findings confirm and extend the hypotheses above, as $\mathrm{CR}$ displayed $\mathrm{N}$-limitation in a few instances and $\mathrm{N}$ and $\mathrm{C}$ co-limitation in nearly all instances.

It is well-known that $\mathrm{N}$ limits primary production throughout broad areas of the ocean (Moore et al., 2013), and our experiments show that GPP responded positively to $\mathrm{N}$ additions in many marine lakes. However, the heterotrophic microbial community also utilizes inorganic nutrients and can be limited by $\mathrm{N}$; this is a result of high microbial $\mathrm{N}$ demands (low $\mathrm{C}: \mathrm{N}$ ratios), high abundances, and their high affinity for $\mathrm{N}$ (e.g., small surface to volume ratios) - factors that apparently lead to microbial control of $\mathrm{N}$ cycling across a wide range of ecosystems (Taylor and Townsend, 2010). Microbial N limitation has been tested in the ocean through experimental $\mathrm{N}$ additions that show changes in activity, abundance, and community composition. Like our experiments, this work shows that microbial responses to $\mathrm{N}$ are complex and commonly depend on more than $\mathrm{N}$ alone. For example, Mills et al. (2008) found that $\mathrm{N}$ and $\mathrm{P}$ co-limited bacterial production in the North Atlantic, while Carlson et al. (2002) found that $\mathrm{N}$ had no effect on its own, but the combination of $\mathrm{N}, \mathrm{P}$, and DOC increased bacterial production in the Sargasso Sea. However, microbial responses vary across different studies: Caron et al. (2000) observed increased bacterial and phytoplankton production in the Sargasso Sea following additions of $\mathrm{N}$ and $\mathrm{P}$-which were not added separatelywhereas Rivkin and Anderson (1997) observed that $\mathrm{N}$ alone increased bacterial production or growth in the Sargasso Sea, Caribbean Sea, and Gulf Stream. These results and our own demonstrate that the quantity, timing, and stoichiometry of organic matter are key determinants of CR and/or bacterial production.

In our experiments, the effects of combined $\mathrm{N}$ and $\mathrm{C}$ additions on $\mathrm{CR}$ and NCP may be explained by several underlying responses. In lakes without a clear response to $\mathrm{N}$ or $\mathrm{C}$ alone, our results are indicative of co-limitation of $\mathrm{CR}$ by $\mathrm{N}$ and labile C. In lakes where $\mathrm{CR}$ did respond to either $\mathrm{N}$ or $\mathrm{C}$, the joint effects of $\mathrm{N}$ and $\mathrm{C}$ were more than additive. One possibility is that this reflects complementarity among different microbial groups. Another possibility is that nitrifying archaea and bacteria respond to the $\mathrm{N}$ additions and draw down DO (this can be a significant sink for DO), but there is little evidence for this in our nutrient data: oxidized $\mathrm{N}$ concentrations were only slightly elevated following $\mathrm{N}$ additions to dark bottles (Table 2). Importantly, coaddition of $\mathrm{N}$ and $\mathrm{C}$ to light bottles yielded negative NCP values and a sharp shift to heterotrophy. This is indicative of rapid microbial response to $\mathrm{C}$ and $\mathrm{N}$ that would ultimately lead to the consumption of DO. A second implication of this finding is that the microbial community represents a significant sink for $\mathrm{N}$, as we found that $55-98 \%$ of added $\mathrm{N}$ was taken up over the course of the incubations (Table 2).

\section{Effects of Light, Temperature, and Oxygen on GPP, CR, and NCP}

In contrast to the strong effects of $\mathrm{N}$ and $\mathrm{C}$ on GPP, CR, and NCP in marine lakes, the effects of light and temperature were comparatively minor. Our regression results showed that although GPP was typically higher closer to the surface, GPP did not correlate significantly with light intensity. Nutrient availability was instead a more important influence on GPP in regression. Despite the lack of correlation between light and GPP when all lakes were assessed together, depth transplants reinforced the importance of light, as samples that were moved to shallower depths increased in terms of GPP, while samples that were moved to deeper depths decreased. Light limitation has been documented in tropical lakes before (Lewis, 1974; Guildford et al., 2003) and the variation in observed responses here can be explained by a combination of transplant distance and the microbial community. For example, HLO likely showed large changes in transplanted GPP because samples underwent the largest depth change $(17 \mathrm{~m})$ and because the lake is holomictic, meaning the photosynthetic community at the bottom of the lake was similar to the upper zone and able to take advantage of the higher light levels. OTM, on the other hand, showed very little change in GPP-likely due to the fact that deep samples that were transplanted to higher light levels possessed photosynthesizers adapted to the light levels at the chemocline, and were not able to take advantage of greater light intensities. This is similar to the phenomenon observed in stratified oceanic environments, where phytoplankton in deeper layers become light saturated at lower light levels than surface phytoplankton (Ryther and Menzel, 1959).

Depth transplants also illustrated the effects of temperature change on CR. Although observed temperature differences were small, such that the maximum temperature difference observed in depth transplants was less than $1^{\circ} \mathrm{C}, \mathrm{CR}$ generally increased in 
bottles moved from deeper, slightly cooler waters to the surface, and vice versa. This is in accordance with metabolic theory (López-Urrutia et al., 2006; Regaudie-de-Gioux and Duarte, 2012), although these increases were rarely significant and were not large in magnitude. Because these are dark bottle incubations, these changes cannot be explained by responses to increases or decreases in GPP driven by variations in light levels at different depths.

Oxygen concentration was also important in predicting GPP and CR within and across lakes. GPP tended to decrease as oxygen increased, while CR displayed a hump-shaped pattern with $\mathrm{DO}$, with highest rates found at intermediate DO concentrations (Figure 5). The correlation between low $\mathrm{O}_{2}$ concentrations and increased GPP is most likely due to the higher concentration of nutrients coming from low oxygen waters. The observation that $\mathrm{CR}$ was highest at moderate oxygen concentrations $\left(\sim 100-160 \mathrm{mmol} \mathrm{O}_{2} \mathrm{~m}^{-3}\right)$ was likely a function of heterotrophic microorganisms being most active at the interface between well-oxygenated surface waters and the nutrient- and labile organic matter-rich deeper waters. However, it is also possible that the intermediate oxygen concentration zone possessed the most microbial activity (for which CR is a rough proxy) as it is an interface between well-oxygenated and low oxygen waters, leading to higher diversity (Beman and Carolan, 2013) and allowing for redundancy and a wider range of responses, which can stabilize ecological function from random physical and biological fluctuations (McGrady-Steed et al., 1997; Naeem and Li, 1997; Bell et al., 2005; Tilman et al., 2006).

\section{Implications for Oxygen, Carbon, and Nutrient Cycling}

Assembled together, our results highlight the links between the production and consumption of DO by GPP and CR, and the dependence of these processes on the availability of nutrients and carbon. In meromictic lakes with steep depth gradients in DO and dissolved nutrients, we found distinct variation in GPP and CR with depth-including strong net autotrophy near the chemocline. The depth of the chemocline is consistent in our data and in earlier work (Hamner et al., 1982; Hamner and Hamner, 1998; Colin, 2009; Meyerhof et al., 2016), suggesting biogeochemical coupling between GPP in oxygenated waters and the regeneration of nutrients in deeper layers. Our experimental additions demonstrate that $\mathrm{N}$ can limit $\mathrm{CR}$, and that this is

\section{REFERENCES}

Bakun, A., Field, D. B., Redondo-Rodriguez, A., and Weeks, S. J. (2010). Greenhouse gas, upwelling-favorable winds, and the future of coastal ocean upwelling ecosystems. Global Change Biol. 16, 1213-1228. doi: 10.1111/j.1365-2486.2009.02094.x

Behrenfeld, M. J., O’Malley, R. T., Siegel, D. A., McClain, C. R., Sarmiento, J. L., Feldman, G. C., et al. (2006). Climate-driven trends in contemporary ocean productivity. Nature 444, 752-755. doi: 10.1038/nature 05317

Bell, T., Newman, J. A., Silverman, B. W., Turner, S. L., and Lilley, A. K. (2005). The contribution of species richness and composition to bacterial services. Nature 436, 1157-1160. doi: 10.1038/nature03891 as common as limitation of $\mathrm{CR}$ by the availability of labile $\mathrm{C}$. As the oceans lose oxygen and low oxygen regions expand, $\mathrm{N}$ loss through anaerobic processes will likely be enhanced, leading to lower $\mathrm{N}$ availability. If $\mathrm{N}$-limitation of $\mathrm{CR}$ is widespread in the ocean, and especially OMZs, this could lead to a negative feedback on CR and slow the overall rate of deoxygenation.

However, $\mathrm{C}$ and $\mathrm{N}$ co-limitation of $\mathrm{CR}$ was far more prevalent in our experiments than $\mathrm{N}$ or C-limitation. To our knowledge, this is first demonstration of this phenomenon in low-oxygen marine ecosystems of any kind, and we found that the magnitude of this response was frequently greatest in deoxygenated lakes. $\mathrm{N}$ and $\mathrm{C}$ co-additions consistently resulted in net heterotrophy, indicating that the relative proportions of $\mathrm{N}$ and $\mathrm{C}$, and their chemical forms, are critical determinants of NCP and net DO consumption. Our results suggest that pulses of $\mathrm{N}$ and $\mathrm{C}$ (but not $\mathrm{N}$ or $\mathrm{C}$ alone) sharply decrease NCP. Further work should examine how variations in the stoichiometry, chemical composition, quantity, and timing of organic matter inputs interact to affect CR and NCP along depth gradients in low-oxygen ecosystems. Our findings are also indicative of substantial uptake of $\mathrm{N}$ by microbial communities. The extent and duration of this $\mathrm{N}$ sink will be regulated by microbial growth efficiency, grazing, and viral lysis-in addition organic matter stoichiometry and nutrient concentrations - underlining the need to understand all aspects of marine ecosystems, and their interactions, in a changing ocean.

\section{AUTHOR CONTRIBUTIONS}

JW, SA, and JB performed field research, analyzed the data, and wrote the paper.

\section{ACKNOWLEDGMENTS}

This work was supported by the NSF Dimensions of Biodiversity Program (OCE-1241255 to JB and Michael Dawson) and by the UC Merced Graduate Division (to JW). We thank the Coral Reef Research Foundation, Dr. Michael Dawson, and NECO Marine for supporting fieldwork, and we thank Dr. Kelly Henry and Curtis Hayden for their help in the field. We would also like to thank Dr. Chris Kello and Angela Winek for their assistance in the development of the manuscript.

Beman, J. M., Arrigo, K. R., and Matson, P. A. (2005). Agricultural runoff fuels large phytoplankton blooms in vulnerable areas of the ocean. Nature 434, 211-214. doi: 10.1038/nature03370

Beman, J. M., and Carolan, M. T. (2013). Deoxygenation alters bacterial diversity and community composition in the ocean's largest oxygen minimum zone. Nat. Commun. 4:2705. doi: 10.1038/ncomms3705

Blight, S. P., Bentley, T. L., Lefevre, D., Robinson, C., Rodrigues, R., Rowlands, J., et al. (1995). Phasing of autotrophic and heterotrophic plankton metabolism in a temperate coastal ecosystem. Mar. Ecol. Prog. Ser. Oldendorf 128, 61-75. doi: 10.3354/meps128061

Bograd, S. J., and Lynn, R. J. (2001). Physical-biological coupling in the California Current during the 1997-99 El Niño-La Niña Cycle. Geophys. Res. Lett. 28, 275-278. doi: 10.1029/2000GL012047 
Breitburg, D. L., Crump, B. C., Dabiri, J. O., and Gallegos, C. L. (2010). Ecosystem engineers in the pelagic realm: alteration of habitat by species ranging from microbes to jellyfish. Integr. Comp. Biol. 50, 188-200. doi: 10.1093/icb/icq051

Bronk, D., See, J., Bradley, P., and Killberg, L. (2007). DON as a source of bioavailable nitrogen for phytoplankton. Biogeosciences 4, 283-296. doi: 10.5194/bg-4-283-2007

Burnett, B., Narita, H., and Harada, K. (1988). Uranium-series isotopes in sediment and water from an anoxic marine lake in Palau, Micronesia. Chem. Geol. 70, 125. doi: 10.1016/0009-2541(88)90551-7

Carlson, C. A., Giovannoni, S. J., Hansell, D. A., Goldberg, S. J., Parsons, R., Otero, M. P., et al. (2002). Effect of nutrient amendments on bacterioplankton production, community structure, and DOC utilization in the northwestern Sargasso Sea. Aquat. Microb. Ecol. 30, 19-36. doi: 10.3354/ame 030019

Caron, D. A., Lin Lim, E., Sanders, R. W., Dennett, M. R., and Berninger, U.-G. (2000). Responses of bacterioplankton and phytoplankton to organic carbon and inorganic nutrient additions in contrasting oceanic ecosystems. Aquat. Microb. Ecol. 22, 175-184. doi: 10.3354/ame022175

Colin, P. L. (2009). Marine Environments of Palau. Honolulu, HI: Mutual Publishing LLC, 416.

Dalsgaard, T., Thamdrup, B., Farías, L., and Revsbech, N. P. (2012). Anammox and denitrification in the oxygen minimum zone of the eastern South Pacific. Limnol. Oceanogr. 57, 1331-1346. doi: 10.4319/lo.2012.57.5.1331

Dawson, M. N. (2006). Island evolution in marine lakes. JMBA Global Mar. Environ. 3, 26-29.

Dawson, M. N., and Hamner, W. M. (2005). Rapid evolutionary radiation of marine zooplankton in peripheral environments. Proc. Natl. Acad. Sci. U.S.A. 102, 9235-9240. doi: 10.1073/pnas.0503635102

del Giorgio, P. A., and Williams, P. J. 1. B. (2005). Respiration in Aquatic Ecosystems. Oxford: Oxford University Press, 328.

Deutsch, C., Brix, H., Ito, T., Frenzel, H., and Thompson, L. (2011). Climate-forced variability of ocean hypoxia. Science 333, 336-339. doi: $10.1126 /$ science. 1202422

Diamond, D. (1997). "Determination of nitrate in brackish or seawater by flow injection analysis," in QuikChem Method 31-107-04-1-A for Lachat Instruments (Milwaukee, WI: Lachat Instruments).

Diamond, D., and Huberty, A. (1996). "Determination of ammonia by flow injection analysis," in QuikChem Method 31-107-06-5-A for Lachat Instruments (Milwaukee, WI: Lachat Instruments).

Doney, S. C., Ruckelshaus, M., Duffy, J. E., Barry, J. P., Chan, F., English, C. A., et al. (2012). Climate change impacts on marine ecosystems. Mar. Sci. 4, 11-37. doi: 10.1146/annurev-marine-041911-111611

Elser, J., Sterner, R., Gorokhova, E., Fagan, W., Markow, T., Cotner, J., et al. (2000). Biological stoichiometry from genes to ecosystems. Ecol. Lett. 3, 540-550. doi: 10.1046/j.1461-0248.2000.00185.x

Francis, C. A., Beman, J. M., and Kuypers, M. M. (2007). New processes and players in the nitrogen cycle: the microbial ecology of anaerobic and archaeal ammonia oxidation. ISME J. 1, 19-27. doi: 10.1038/ismej.2007.8

Gilly, W. F., Beman, J. M., Litvin, S. Y., and Robison, B. H. (2013). Oceanographic and biological effects of shoaling of the oxygen minimum zone. Ann. Rev. Mar. Sci. 5, 393-420. doi: 10.1146/annurev-marine-120710100849

Gist, N., Serret, P., Woodward, E. M. S., Chamberlain, K., and Robinson, C. (2009). Seasonal and spatial variability in plankton production and respiration in the Subtropical Gyres of the Atlantic Ocean. Deep Sea Res. II 56, 931-940. doi: $10.1016 /$ j.dsr2.2008.10.035

Gregg, W. W., Casey, N. W., and McClain, C. R. (2005). Recent trends in global ocean chlorophyll. Geophys. Res. Lett. 32, 1-5. doi: 10.1029/2004GL021808

Gruber, N. (2008). The Marine Nitrogen Cycle: Overview and Challenges. Nitrogen in the Marine Environment, 2nd Edn. Cambridge, MA: Academic Press.

Gruber, N., and Sarmiento, J. L. (1997). Global patterns of marine nitrogen fixation and denitrification. Global Biogeochem. Cycles 11, 235-266. doi: 10.1029/97GB00077

Guildford, S. J., Hecky, R. E., Taylor, W. D., Mugidde, R., and Bootsma, H. A. (2003). Nutrient enrichment experiments in tropical great lakes Malawi/Nyasa and Victoria. J. Great Lakes Res. 29, 89-106. doi: $10.1016 / \mathrm{S} 0380-1330(03) 70541-3$
Hamner, W., Gilmer, R., and Hamner, P. (1982). The physical, chemical, and biological characteristics of a stratified, saline, sulfide lake in Palau. Limnol. Oceanogr. 27, 896-909. doi: 10.4319/lo.1982.27.5.0896

Hamner, W. M., and Hamner, P. P. (1998). Stratified marine lakes of Palau (Western Caroline islands). Phys. Geogr. 19, 175-220.

Huberty, A., and Diamond, D. (1998). "Determination of phosphorus by Flow injection analysis colorimetry," in QuikChem Method 31-115-01-3-A for Lachat Instruments (Milwaukee, WI: Lachat Instruments).

Kalvelage, T., Lavik, G., Jensen, M. M., Revsbech, N. P., Löscher, C., Schunck, H., et al. (2015). Aerobic microbial respiration in oceanic oxygen minimum zones. PLoS ONE 10:e0133526. doi: 10.1371/journal.pone.0133526

Karl, D. M., and Knauer, G. A. (1991). Microbial production and particle flux in the upper $350 \mathrm{~m}$ of the Black Sea. Deep Sea Res. A. 38, S921-S942. doi: 10.1016/S0198-0149(10)80017-2

Karstensen, J., Stramma, L., and Visbeck, M. (2008). Oxygen minimum zones in the eastern tropical Atlantic and Pacific oceans. Prog. Oceanogr. 77, 331-350. doi: 10.1016/j.pocean.2007.05.009

Katija, K., and Dabiri, J. O. (2009). A viscosity-enhanced mechanism for biogenic ocean mixing. Nature 460, 624-626. doi: 10.1038/nature08207

Keeling, R. F., Körtzinger, A., and Gruber, N. (2010). Ocean deoxygenation in a warming world. Mar. Sci. 2, 199-229. doi: 10.1146/annurev.marine.010908.163855

Lam, P., and Kuypers, M. M. (2011). Microbial nitrogen cycling processes in oxygen minimum zones. Ann. Rev. Mar. Sci. 3, 317-345. doi: 10.1146/annurev-marine-120709-142814

Landing, W. M., Burnett, W. C., Lyons, W. B., and Orem, W. H. (1991). Nutrient cycling and the biogeochemistry of manganese, iron. and zinc in Jellyfish Lake, Palau. Limnol. Oceanogr. 36, 515-525. doi: 10.4319/lo.1991.36.3.0515

Lewis, W. M. (1974). Primary production in the plankton community of a tropical lake. Ecol. Monogr. 44, 377-409. doi: 10.2307/1942447

López-Urrutia, A., San Martin, E., Harris, R. P., and Irigoien, X. (2006). Scaling the metabolic balance of the oceans. Proc. Natl. Acad. Sci. U.S.A. 103, 8739-8744. doi: $10.1073 /$ pnas. 0601137103

Lyons, W. B., Lent, R. M., Burnett, W. C., Chin, P., Landing, W. M., Orem, W. H., et al. (1996). Jellyfish Lake, Palau: regeneration of C, N, Si, and $\mathrm{P}$ in anoxic marine lake sediments. Limnol. Oceanogr. 41, 1394-1403. doi: 10.4319/lo.1996.41.7.1394

Martiny, A. C., Pham, C. T. A., Primeau, F. W., Vrugt, J. A., Moore, J. K., Levin, S. A., et al. (2013). Strong latitudinal patterns in the elemental ratios of marine plankton and organic matter. Nat. Geosci. 6, 279-283. doi: 10.1038/ngeo1757

McGrady-Steed, J., Harris, P. M., and Morin, P. J. (1997). Biodiversity regulates ecosystem predictability. Nature 390, 162-165. doi: 10.1038/36561

Meyerhof, M. S., Wilson, J. M., Dawson, M. N., and Michael Beman, J. (2016). Microbial community diversity, structure and assembly across oxygen gradients in meromictic marine lakes, Palau. Environ. Microbiol. 18, 4907-4919. doi: 10.1111/1462-2920.13416

Mills, M. M., Moore, C. M., Langlois, R., Milne, A., Achterberg, E. P., Nachtigall, K., et al. (2008). Nitrogen and phosphorus co-limitation of bacterial productivity and growth in the Oligotrophic Sub-Tropical North Atlantic. Limnol. Oceanogr. 53, 824-834. doi: 10.4319/lo.2008.53.2.0824

Moore, C., Mills, M., Arrigo, K., Berman-Frank, I., Bopp, L., Boyd, P., et al. (2013). Processes and patterns of oceanic nutrient limitation. Nat. Geosci. 6, 701-710. doi: 10.1038/ngeo1765

Morán, X. A. G., Fernández, E., and Pérez, V. (2004). Size-fractionated primary production, bacterial production and net community production in subtropical and tropical domains of the oligotrophic NE Atlantic in autumn. Mar. Ecol. Prog. Ser. 274, 17-29. doi: 10.3354/meps274017

Naeem, S., and Li, S. (1997). Biodiversity enhances ecosystem reliability. Nature 390, 507-509. doi: 10.1038/37348

Orem, W. H., Burnett, W., Landing, W., Lyons, W., and Showers, W. (1991). Jellyfish Lake, Palau: early diagenesis of organic matter in sediments of an anoxic marine lake. Limnol. Oceanogr. 36, 526-543. doi: 10.4319/lo.1991.36.3.0526

Paulmier, A., and Ruiz-Pino, D. (2009). Oxygen minimum zones (OMZs) in the modern ocean. Prog. Oceanogr. 80, 113-128. doi: 10.1016/j.pocean.2008.08.001

Paulmier, A., Ruiz-Pino, D., and Garçon, V. (2011). $\mathrm{CO}_{2}$ maximum in the oxygen minimum zone (OMZ). Biogeosciences 8, 239-252. doi: 10.5194/bg-8-239-2011 
Regaudie-de-Gioux, A., and Duarte, C. M. (2012). Temperature dependence of planktonic metabolism in the ocean. Global Biogeochem. Cycles 26, 1-10. doi: 10.1029/2010GB003907

Rivkin, R. B., and Anderson, M. R. (1997). Inorganic nutrient limitation of oceanic bacterioplankton. Limnol. Oceanogr. 42, 730-740. doi: 10.4319/lo.1997.42.4.0730

Robinson, C., and Williams, P. J. 1. B. (2005). "Respiration and its measurement in surface marine waters," in Respiration in Aquatic Ecosystems, eds P. A. del Giorgio and P. J. l. B. Williams (Oxford: Oxford University Press), 147-180. doi: 10.1093/acprof:oso/9780198527084.003.0009

Ryther, J. H., and Menzel, D. W. (1959). Light adaptation by marine phytoplankton. Limnol. Oceanogr. 4, 492-497. doi: 10.4319/lo.1959.4.4.0492

Schroeder, S. (1997). "Determination of nitrite in brackish or seawater by flow injection analysis," in QuikChem Method 31-107-05-1-A for Lachat Instruments (Milwaukee, WI: Lachat Instruments).

Serret, P., Robinson, C., Fernández, E., Teira, E., and Tilstone, G. (2001). Latitudinal variation of the balance between plankton photosynthesis and respiration in the eastern Atlantic Ocean. Limnol. Oceanogr. 46, 1642-1652. doi: 10.4319/lo.2001.46.7.1642

Stramma, L., Johnson, G. C., Sprintall, J., and Mohrholz, V. (2008). Expanding oxygen-minimum zones in the tropical oceans. Science 320, 655-658. doi: $10.1126 /$ science. 1153847

Taylor, P. G., and Townsend, A. R. (2010). Stoichiometric control of organic carbon-nitrate relationships from soils to the sea. Nature 464, 1178-1181. doi: 10.1038/nature08985

Tiano, L., Garcia-Robledo, E., Dalsgaard, T., Devol, A. H., Ward, B. B., Ulloa, O., et al. (2014). Oxygen distribution and aerobic respiration in the north and south eastern tropical Pacific oxygen minimum zones. Deep Sea Res. I 94, 173-183. doi: 10.1016/j.dsr.2014.10.001
Tilman, D., Reich, P. B., and Knops, J. M. (2006). Biodiversity and ecosystem stability in a decade-long grassland experiment. Nature 441, 629-632. doi: 10.1038 /nature 04742

Ulloa, O., Canfield, D. E., DeLong, E. F., Letelier, R. M., and Stewart, F. J. (2012). Microbial oceanography of anoxic oxygen minimum zones. Proc. Natl. Acad. Sci. U.S.A. 109, 15996-16003. doi: 10.1073/pnas.12050 09109

Ward, B. B., Devol, A. H., Rich, J. J., Chang, B. X., Bulow, S. E., Naik, H., et al. (2009). Denitrification as the dominant nitrogen loss process in the Arabian Sea. Nature 461, 78-81. doi: 10.1038/nature08276

Williams, P. J. l. B. (2000). "Net production, gross production and respiration: what are the interconnections and what controls what," in The Changing Ocean Carbon Cycle: A Midterm Synthesis of the Joint Global Ocean Flux Study, eds R. B. Hanson, H. W. Ducklow, J. G. Field, and Joint Global Ocean Flux Study (Cambridge: Cambridge University Press), 37-60.

Wright, J. J., Konwar, K. M., and Hallam, S. J. (2012). Microbial ecology of expanding oxygen minimum zones. Nat. Rev. Microbiol. 10, 381-394. doi: $10.1038 /$ nrmicro2778

Conflict of Interest Statement: The authors declare that the research was conducted in the absence of any commercial or financial relationships that could be construed as a potential conflict of interest.

Copyright (c) 2017 Wilson, Abboud and Beman. This is an open-access article distributed under the terms of the Creative Commons Attribution License (CC BY). The use, distribution or reproduction in other forums is permitted, provided the original author(s) or licensor are credited and that the original publication in this journal is cited, in accordance with accepted academic practice. No use, distribution or reproduction is permitted which does not comply with these terms. 